\title{
STATUTEN DER SUSTEREN REGULARISSEN DES CAPITTELS VAN HOLLANT,
}

\author{
MEDEGEDEELD DOOR
}

B. J. M. DE BONT.

Met "Capittel van Hollant" wordt hier bedoeld de congregatie der Reguliere Kanunnikken van de orde van St. Augustinus te Delft, welke wel bijna gelijktijdig met die van Windesheim werd opgericht, doch zich niet met haar vereenigde en afzonderlijk bleef bestaan. Bij de congregatie van Delft sloten tal van mannen- en rrouwenkloosters in Holland zich aan; en daar bij oprichting dier congregatio het klooster Sion te Delft een der voornaamste was, zoo werd het kapittel daarnaar genoemd.

Tot de twaalf kloosters, welke in $1437^{1}$ ) bij Sion waren aangesloten, behoorde 0. a. het St.-Maria-Magdalena-convent te Amsterdam 2). Reeds vóór 1411 hadden enkele godvruchtige vrouwen onder bescherming van de H. Maria Magdalena zich vereenigd in Willems die Bruyne Roel of ssoen huisinghe, gheleghen in Grijmnesse. Zij

1) Brief van Walraven van Meurs, bisschop van Utrecht: Bijdr. Gesch. Bisd. o. Haarl., Deel XVI, blz. 59.

2) Niet te verwarren met het klooster van Maria Magdalena in Bethaniēn. Zie mijn Voormalige Amsterdamsche Vrouroenkloosters: Bijdr. Gesch. Bisd. v. Haarl., Deel XXI, XXII en XXIII. 
volgden eerst de "derder oerde Sinte Franciscus", en toen zij zich al meer en meer tot de vijftiende-eeuwsche kloosterhervorming voelden aangetrokken, sloten zij zich aan bij het Kapittel van Sion. De statuten ${ }^{1}$ ), welke wij hier laten volgen, zijn af komstig van genoemd klooster, zooals blijkt uit het inschrift op de binnenzijde van het voorblad van den perkamenten band Liber monialium sancte Marie Magdalene in Amstelredam.

Het HS., in 8 ro, is in Noord-Hollandsch dialect met tal van afkortingen en met een zeer duidelijke hand op perkament geschreven. Het bevat 53 bladzijden met ongeveer 3200 regels schrift en is in twee deelen verdeeld, voorafgegaan door een "prologus". De allereerste hoofdletters van de inleiding en het begin van het eerste en tweede deel zijn aanmerkelijk grooter dan de overige en in zacht blauwe kleur met roode versiering, welke langs de geheole linker marge loopt. De hoofdstukken en de eerste letter van de kapittels zijn, evenals de aanstrepingen der hoofdletters, in rood. Op de interpunctie is niet gelet; slechts hier en daar vindt men de gewone punt waar een komma moet $\operatorname{staan}^{2}$ ).

Het HS. dagteekent uit het midden van het tweede kwartaal der XVde eeuw. Waarschijnlijk is de codex geschreven omtrent 1437 toen het klooster tot het Kapittel van Sion was toegetreden. In 1484 werd het echter bï Windesheim ingelijfd, zooals wij moeten veronderstellen uit den brief van Theodericus, prior $\operatorname{van}$ het buis der $\mathrm{H}$. Maria in Windesheim, waarbij bij het convent in alle voorrechten van het Fraterhuis te Windesheim doet deelen ${ }^{3}$ ).

De hierna volgende statuten zijn niet geheel onbekend; hetgeen te verklaren is uit het feit, dat vele kloosters,

1) In mijn bezit. Aangekocht op een veiling bij Fred. Muller en Co.

2) Voor de interpunctie, het gebruik van hoofdletters en de samenstelling van enkele van elkander gescheiden of aan elkander gevoegde woorden, heb ik mij zooveel mogelijk gehouden aan de voorschriften van het Historisch Genootschap.

3) Zie mijn Voormalige Amsterdamsche Vrouwenkloosters. Deel XXII, blz. 249.

VI. 
alvorens bun grondwet te maken, eene commissie benoemden die, als leidraad voor de te maken statuten, zich bodienen moest van de oudere en nieuwere reglementen van andere reguliere kloosters.

Prof. Dr. Gallee heeft twee dergelijke statuten roor vrouwenkloosters uitgegeren; een in het latijn, af komstig uit "Albergen" in Overijssel, en een in het Middelnederlandsch, af komstig uit "Bethlehem" in den Bangerd buiten Hoorn, met een voorwoord van Dr. F. Pïper ${ }^{1}$ ).

Eene nauwkeurige vergelijking van die statuten met die van het Maria Magdalena-convent doet zien, dat het laatstgenoemde reglement op enkele plaatsen zeer verschilt met de beide statuten hierroor genoemd. Klaarblïkelijk is de grondwet van het Maria Magdalena-klooster uit een latijnsch handschrift vertaald, want meermalen wordt ter bekorting van het Kapittel verwezen naar het manuaal zooals "gheteikent is int selve capittel in den latyn".

Het zoude te reel plaatsruimte rragen, indien wij alle verschilpunten hier opsomden. Wij zullen ons dus beperken tot de voornaamste.

Noch in de statuten van ${ }_{n}$ Albergen", noch in die van "Bethlehem" komt voor "Van den generael capittel, dat "eerste capittel"; evenmin "Van die rectoer ende syne ghesellen"; noch "Van den doden na der doot", „Van die tyt to studeren" enz.

Het eerste Kapittel is vooral daarom merkwaardig omdat het bewijst, dat de statuten zijn die van Sion: $n^{\text {alle }}$ i $a$ er sellen die rectoren der nonnen van Sinte Marienpoel ${ }^{2}$ ) buten Leyden, als die prioers tesamen comen tot Syon" enz.

In het reglement $\operatorname{van}$ Sion verschillen de uren van slapen, opstaan en luiden; evenzoo de jaren roor de aanneming der kloosterlingen en die voor stemgerechtigdheid. Overeenkomst bestaat evenwel met de statuten van Windes-

1) Arch. voor Nederl. Kerkgesch., 1895, blz. 228 en volg.

2) Marienpoel behoorde tot die kloosters, welke in 1437 bij het Kapittel van Sion waren aangesloten. 
heim, daar waar gesproken wordt van de diffinitoren en van de donatinnen; terwijl in tegenstelling van die van Bethlehem, het klooster van Maria Magdalena niet stond onder het gezag ran "ons(en) ghenedighen heren (den bisschop) van Utrecht", maar onder dat van het kapittel van Sion.

Ik eindig deze korte inleiding, daar ik vrees misbruik te gaan maken van de plaatsruimte, welke mij zoo welwillend wordt verleend.

Amsterdam, October 1907. 
1 recto. Dit is dat prologus van d' statuten der susteren regularissen des capittels van Hollant.

Die heilighe leraer ende gloriose confessoer Christi Augustyn vol des heiligen Gheests, die screef een reghel na(ar) den leven der heilighen apostelen, welke hi heeft alsoe mitten soute der besceijdenheit ghematicht, dat binae alle menschen, die de werelt laten willen ende Christus willen volghen, armen ende ryck, cranc ende starc dese reghel houden moghen. Ende so wie die minnen ende volghen, die wanderen enen conincliken wech, ende wederkeren overmits haerre heiligher leidinghe totten gloriosen ende ewighen vaderlande. Hierom ist recht, dat wie onder een reghel ende eenre professien loofte te samen verbonden te sijn, ghelycformich in wisen ende seden kersteliker religien gheronden worden, opdat eenheit die men houden sel in de herten van binnen mitten bande des rredes roede ende toene ghelijcformicheit ghehouden in de zeden van buten. Enade opdat men dit gadeliker ${ }^{1}$ ) ende volcomeliker totten love Goods ende onsen voertganc houden moghen, so hebben wi die dinghen die men doen sel in scrifte gheset ende nae ghelegentheit der steden ende ghedaente der personen na rechter bescheydenheit ghematicht, opdat die vuerighe hebben dat si begheren, ende die traghe of slappe dat si ontsien; oec mede den crancken niet en ontbreket, dat si behoeven. Ende desen ghescrifte ende

1 vo. insettinghe en is nyement gheoerloft jet of te doen of toe, of jet to rerwandelen, mer mit oetmoedigher eenvoudicheit sel elc pinen 2) na(ar) sijn vermoghen dit te volbrenghen. Opdat wi dan der eenheit ende vrede ende salicheit onser husen voersien, so willen wi ende declarieren, dat onse insettinghe of statuten niement en verbinden tot enigher sonde, mer tot sulker

1) Behagelijk, geschikt ook aangenaam.

2) Zich berlijtigen. 
pine 1) ende penitencie als ene yeghelyc van haren oversten gheset sel worden; ten waer of yement die niet houden en woude uit versmadenisse. Laet ons nochtan wachten over versumelheit ende onachsomheit deser heiliger wisen ende ghewoenten, opdat wi niet dorre, onbeweghen ende onberoelic en worden ende allenken tot argheren dinghen en dalen. Want dat plech den roekelosen toe te comen, als si van versumelheit goeder ghewoenten beghinnen min bedruct to worden. Tot desen sel nochtan $\mathrm{na}(\mathrm{ar})$ inhout onser privilegien elke priorinne in haren convent mit elc van den susteren dies behoeven bi rade ende consent des rectoers macht hebben te dispensieren alst haer tyt sel duncken wesen in dien dinghen die der wisen ende seden van buten ende lichameliker oefeninghe toe behoren. Nochtan en sel si niet dispensieren mit dat hele convent haer vasten te breken of diergelije buten consent des rectoers. Si sel oec selve die dispensaci ghenieten als die ander susteren. So wie dat behoeftich is stadelic of langhe tijt die strenghicheit der ghemeenre insettinghe haer verlicht te worden, die sel te kennen gheren haer noetorsticheit ${ }^{2}$ ) bi oeriof des rectoers ende der priorinne in den capittel voer die susteren ende also van

2. der priorinne berm(har)ticheit begheren. Soe wie van den rectoer, van der priorinne of enen anderen die enighen dienst heeft yet begheert dat haer gheweighert wort, ist dat si daarnae datselve van enen anderen eysschet, so en sel sijs niet laten, si en selt segghen, dat haer die ander dat weygherde. Die suppriorinne, als die priorinne niet bi hant en is, so sel si swaerliker daeran comen te dispensieren of yet oerlof te gheren dat men van haer begheert. Dit vermanen wi hem allen ende een yghelic bisonder, dat si boven alle dinghen pinen minnen ende puerheit des herten overmits goede oefeninghe te vercrighen ende haren evemenschen mit gheelre $\mathrm{h}(\mathbf{a r})$ ten te doen, dat si wouden dat men hem dede. Ende dat si alle haer naersticheit ende meninghe daertoe keren, dat si God boven alle dinc minnen ende hem overmits scoenheit des inwendighen menschs begheren te behaghen; alle ghescepen dinghen om liefte haers brudegoms versmadende ende mit eerwaerdicheit des herten onderdanich sijn ende ghelaten onder hare oversten; ende ummer minliken wanderen ende ommegaen mit haren susteren ende oec buten

1) Straffen.

2) Nooddruft. 
tiden des dienst Goods als neerachtige byen vlitich sijn in haren hantwerc, opdat si haer broot niet leechlich etende, maer hen selve ende die arme menschen mit haren arbeit moghen voeden ende dat loon der salicheit dat den arbeiders is ghelovet van Christo, den heiligen Wedergherer, moghen ontranghen. Hierom hebben wi desen boec mit doersienighen ende ripen raden ende wel bedochte ghemoede naerstelic bescreven ende

2 ro. in tween boeken of distinctien mit capittelen ghedeilt, opdat een yghelic te reder vinden en te bet onthouden mach datgheen, dat hem toebehoert te doen. Welke kustumen ende observancien alle onse susteren oetmoedelic ende naerstelic pinighen sellen to volbrenghen ende te houden als eenrehande penitencie die hem gheset is in verlatenis haere sunden, opdat si bi utwisinghe van desen ghescrifte van doechden in doechden voertgaen moghen ende sien mit volhertighe rrolicheit sonder eynde God der Goden in Syon. Ende opdat si te vaster ghevesticht worden in onser herten, so willen wi dat men se twewerf des iaers voer dat convent lesen sal, eens na pinxter ende eens na dertienendach.

Hier beghinnen die capittelen der eerster distinctien.

$\nabla$ an den generaal capiltel $\mathrm{I}$.

Van die iaerlixe visitacie IJ.

Van die rectoer ende sijn ghesellen IJ.

$\nabla$ an die kiesinc der priorinnen IIJ.

Van die priorinne ende hoe si haer hebben sel nadat si ghecoren is $\nabla$.

Pan die suppriorinne VI.

Van die procuratrix VII.

Van die kelrewaert VIII.

Pan die reventerwaert $\mathrm{IX}$.

$\vec{V}$ an die siecwaert $\mathrm{x}$.

Tan die vesteryewaert $\mathrm{xI}$.

Van die sacrista Xus.

Van die contrix IrIJ.

Van die (h)ebdomedaria ${ }^{1}$ ) xnJ.

Van den doden na der doot xr.

1) Wekelijksch. Bij .: lijst van werkzaambeden, wat er iedere week moet gedaan worden. Rooster. 
Van die armaria 1) xry.

Bier beghint die eerste distinctie. $\nabla$ an den Generaal capittel, dat eerste capittel.

3. Opdat wi in allen onsen husen na die reghel ende insettinghe des capittels ordinerlic leven moghen, so sellen alle iaer op ten derden sonnendach na paeschen die rectoren der nonnen van Sinte Marienpoel buten Leyden, als die prioers te samen comen tot Syon, of daert die ouste prior om seker saken goetduncken sel, om te verspreken van die ghemeen voertganc ende orbaer of andere noetortige saken .die den husen $\tan$ onser colligaci aengaen. Elke rectoer sel eer hi utreiset mitten capittelaren syns huus van den saken der oerden verspreken ende in een cedel teikenen dat oerbaer is int ghemeen vercallet. Oec mede sel bi mit hem brenghen die namen der professider susteren, vaders ende moeders, susters ende broeders ende die mit hem wonen; die binnen siaers sijn ghesturven.

Des manedaghes als men dat capittel beghinnet sel men in allen husen onser cloesteren devotelic misse singhen van den heilighen Gheest, opdat hi der vaders herten ingheren wie dat dient ter eeren Goods ende salicheit der zielen. Oec sellen die susteren dan lesen der heilighen Gheest getiden. Die saken des capittels sellen gheeyndet worden doer die ousten prior mitten diffinitoers. Sie sellen oec in allen husen visitierres scicken to voersien dat een prior of twee mit een rectoer visitieren sellen die susteren ende dat si malcander in een iaer niet en visitieren.

Datter in den capittel ghesloten is mit die namen der doden sel die rectoer te huus brenghen, ende dat voer die susteren dient sel hi hem int ghemeen laten lesen.

3 vo. Ende so wat cost daervoer den ghemenen eerbaer ghedaen wort, sel een yghelic voer hem betalen eer hi van daen sceidet. Ist dat enich haus der susteren tusschen tiden enighe saec ${ }^{2}$ ) heeft, dat sel die rectoer des huus den ousten prior laten weten, welke hi doer hem selven of mit sinen ghecoren broeders eynden mach. Ten waer of die sake groot waer, so soude hi die diffinitores of sommighe van den vaderen te samen roepen, ende soe die saec eynden ende den generael capittel oft noot-

1) Kast in ' $t$ algemeen. Hier de zuster die het opzicht heeft over de boekenkast.

2) Geding. 
waer daerof reden gheven. Deze cost die hier van ghedaen wort, sel dat huus betalen die die sake haer is.

Gheen huus ons capittels en is gheoerloft voertan te ontfaen enighe persone van anderen husen ons capittels sonder oerlof des generaals capittels, ten waer dat die ouste prior of die visitierers bi sijn consent enighe persoen verseynde in een ander huus om penitenci te doen. Ende dan sel dat huus, daer die persoen utghenomen wort, des persoens cost betalen na(ar) goetduncke des generaels capittels. Oec en moeten gheen broederhuus noch susterhuus enighe proveniers annemen sonder oerlof des generaels capittels. Ende alle die prioers; rectoers, priorinnen, bro(e)deren ende susteren sellen ghehouden wesen alle die insettinghe des generaels capittels sonder wederspreken vast ende trouwelike houden.

Van die iaerlixe visitaci is capittel.

In den name der heiligher ende onversceydenre Drieroudicheit sel men alle iaer eens te minsten om die heilighe deroci in onsen husen te bet staende te houden elc huus visitieren. Die vaders sellen altoes visitieren die van onsen generael capittel 4. alle iaer dier toe gheschict worden. Men sal alre eerst eer men die visitaci beghint spreken mitten rectoer der susteren des convents dat men visitieren sel ende ondervraghen hem van die staet des convents, van ghesachtheit ende vrede der personen; hoe dat si hem hebben in alle observancien ende costumen der oerden; dermede van den broeders die mit hem wonen, ende ontfanghen daerof sijn bevoelen ende hoeneer hi aldus ghedaen heeft ende alle die nonnen des huus dat men visitieren sel vergadert sijn ende ootmoedelic ghevisitiert to wesen op haer knyen begheert hebben, sel men lesen, als men int generael capittel doet Ad te levari; Gloria Patri; Sicut erat; Kiriel (sic); Christiel (sic) Kiriel (sic) ${ }^{1}$ ); Pater noster; Et ne nos; Salvas fac ancillas tuas; Deus meus sperantes in te; Mitte nobis auxilium de sancto et de Syon tuere nos; Domine Deus virtutum converte nos et ostende faciem tuam et salvi erimus; Domine exaudi; Dominus vobiscum; Oremus: Deus qui corda fidelium Sancti Spiritus illustratione docuisti, da nobis in eodem Spiritu recta sapere et de eius semper consolatione gaudere; Pretende Domine fidelibus tuis dexteram celestis auxilii, ut et to toto corde perquirant et quae digne postulant assequantur;

1) Kyrie Elyson; Christe Eleyson. 
Actiones nostras quaesumus Domine et aspirando preveni et adiuvando prosequere ut cuncta nostra operacio et a te semper incipiat et per te coepta finiatur. Per Christum Dominum.

Ende alsdan een vermaninghe der deuchden ist dattet so dient gheschict is. Ende als si hem die manier van d' visitacien onderseit ende ghelesen hebben, so sellen si hem ghebieden

4 vo. van Goodsweghen ende van des ghemeens capittelsweghen, dat ean ygelic segge van der priorinne, van malcander ende van allen die staet des huus daer he gherraghet wort ende hem wroeghens ${ }^{1}$ ) of beterinc waerdich dunct. En in gheenrewijs noch om lief, noch om leet, noch om vrese wille of enighe oersake die waerheit en verswighe, opdat die huse in doechden ende in devocie te bet staende moghen bliven. Desghelijc sellen oec die rectoer ende daeran die priorinne bi ghehoersamheit ghebieden. Men selre nauwe toesien, dat men nyement geen scout op en legghe die men niet claerlic proeven en mach. Ende so wat eens in den capittel ghecorrighiert is, dat en sal men die visitierres niet aenbrenghen. Die visitierres sellen hem oec wachten dat si elken gheest niet lichtelic en gheloren ende niement ut quaden vermoeden en oerdelen. Als hem aldus gheboden is, ende die caert der laetster vicitacien in teghenwoerdicheit alle der nonnen ghelesen is, gaen die susteren van daen ende men beghint se dan bisonder te horen voer een veynster mit tralien ende mit een cleet. Eerst vernemen si of die priorinne om sorghe der vicitacien mitten personen des huus enich heymelic verbant ghemaect heeft om enighe dinghen te verberghen ende is dat soe, soe sel men den susteren dat verbant ofnemen en die priorinne sel men swaerlic corrigieren. Si sellen naerstelic ondervraghen of die voergaende visitacie wel waerghenomen is, ende die si daer gebreclic in vinden, si si overste of ondersaet, als dieghene die onghehoersamich sijn, penitencie setten.

5. Si sellen oec mit naersticheit vernemen, niet anghesien enighe gunst, die in een verderfnis der religien ghetoent wort, van versumenisse der priorinne of si die ghebreken die si an die susteren mercket of hoert sonder utneminc der personen wel corrigiert; of si die personen des huus goede exempel voerdraecht; of si die observancien des capittels wel doet houden; of si yet roekeloes is in haerre wanderinghen; of si yet sinlic of waerlic is; of si anderen devoten menschen in rechter cari-

1) Wroeging. 
taten daer sijs behoeven bistaet; of si mitten personen des huus ende mit waerliken menschen bequaemlike wanderen can in rechter vreedsamheit. Si sellen oec vernemen of dat ghemeen convent wel terreden is; of si minlic onder malcander wanderen, ende ist dat si daer onvrede vinden, so sellen si die sake mit alre naersticheit ondertasten en die sculdighe swaerlic corrigieren. Voert sellen si vernemen of die personen des huus haer reghel houden; of si na den statuten ende observancien der oerde leven; in niet eighens te hebben; in silenci te houden; in zuverheit, in ghehoersamheit des rectoers ende der priorinnen ende in onderlinghe reverencie; in te comen te kercken; in te doen den dienst Goids; in abstinencien of si yet heymelic te samen spreken, of si vlitich sijn in de ghemenen arbeit ende haren hantwerc. Of si yet curioes sijn in haren habyt; of si murmuraci ende afterspraec scuwen; of si looflic haer scult in den capittel beliden; of si die ghebreken ghenoech vermanen; of si

5 vo. sijn oetmoedich in berispinghe ende beweechlic in correctien. Die visitierres behoeren hem seer nauwe te wachten, dat si niet lichtelic elken gheest ${ }^{1}$ ) en gheloven ende sonderlinc denghenen diet scoon utsetten konnen ende wijs sijn in haren oghen. Voert om te weten die staet der tijtliker dinghen, sel men ondersoeken oft huus beswaert is mit sculde ende hoevele; niet nochtan wien si sonderlinc sculdich sijn, noch of si yemants dinghen op ghelove hebben ghenomen te houden ende hoeveel. Ende ist dattet convent met enighe sculde bezwaert is sonder enighe redelike saken, die den rectoer ende die priorinne of die procuratrix ontsculdighen, dat sel billics haer scout wesen. Van alle dese dinghen voernoemt sel men alle die capittularen mit besceydenheit ondersoeken. Voert sel men vander priorinne ende van vier of vijf ran de outsten susteren vernemen hoe hem dat ghemeen convent beloeft ende tevreden is van binnen ende van buten; $\operatorname{van}$ den wisinghe ${ }^{2}$ ) ende wanderinghe haers rectoers. Ende vernemen si yet dat beteringhe waerdich is, dat sellen si hem alleen bisonder vermanen ende voersien mit naersticheit dattet ghebetert worden. Oec sellen si ondersoeken van wanderinghe ende vrede der broederen ende ander die mitten rectoer wonen. Si sellen oec naerstelic ondersoeken of dat slot wel bewaert wort, ende is daer ghebrec in, dat sellen si sonder

1) Verhaal, geschiedenis.

2) Aanwijzingen. 
utnemen der personen zwaerlike corrigieren. Het is te weten, dat die visitierres in den husen die si visitieren volle macht hebben die ghebreken te corrigieren.

6. Alsdan alle die susteren des huus vergadert sijn so doet men die relaci eerst den donaten ${ }^{1}$ ), dan den conversinnen ${ }^{2}$ ), daerna den noricien, daerna den nonnen die gheen capittelares en sijn, ten laesten den capittularen. Ende als die priorinne Venie bidt om haire reverencie, staet dat convent op, thent ${ }^{3}$ ) die visitierres haer hieten opstaen. Ende dan op haer knyen staende bidt si absolva van haren dienst, desghelijc mede die suppriorinne. Mer alle die ander officialen en sellen dese tijt om gheen absolva bidden. Die visitierres sellen hem wachten, dat si die ghebreken des huus dat si visitieren nyement en vertellen dan die ouste prior of in den generaal capittel of des to doen waer. Die broeders die mitten rectoer wonen die sel men buten den slote mitten rectoer visitieren. Na der visitacien sellen die visitierres die merckelicste ghebreke in een cart ${ }^{4}$ bescriven ende daer laten, ende die sel men alle iaer vierwerf lesen. Eerst na die visitacie in teghewoerdicheit alle der susteren als dat dient op sinte IansEvangelistendach, opten manendach na paesschen ende in der naester visitaci. Voert sellen die visitierres haren dienst trouwoliken doen, ende sonder merkelike saken niet langher bliven in den huysen die si visitieren. Si sellen oec daer toesien dat si behoudelic disciplijn ende correctie der oerden meerre vrede in den husen afterlaten dan si daer vonden. Ende in gheenre [achter "gheenre" staat in margine h u c usque que legatur] wijs en moeten si van den huysen die si visitieren enighe gave of cleynode of enighe dinghen cleyn of groot ut oersaec der visi-

6 vo. tacien eysschen of ontfanghen of yement van harentweghen. Voert so wat redelike cost, dat die visitierres segghen dat si om der huysen willen die si visitieren ghedaan hebben of doen sellen, dat sel elke huse na dattet hende of verre gheleghen is sijn aendeel betalen.

Van die rectoer ende sijn ghesellen wJ (cappittel) ${ }^{5}$ ).

1) Kostgangers. Zij deden niet de groote beloften maar moesten de gewone regels volgen.

2) Werkzusters.

3) Totdat.

4) Blad papier.

5) Dit kapitel komt noch in het hs. van "Betlehem", noch in dat van nAlbergen" voor. 
Alst noot is enighe husen een rectoer te ordineren, so sel die oversten prior ontbieden die diffinitoers van dien iaer. Voer den sommighen nochtan mach hi enighe ander vaderen ontbieden ende doen alst gheteikent is int selve capittel van den rectoer in den latyn.

Van die kiesinghe der priorinne wr capittel.

Die kiesinghe der priorinne, alst van node sel wesen, sel in allen formen ende manieren gheschien na den gheesteliken rechte in vasten, ghebeden ende ander hantieringhe alst in den selven capittel in den latijn gheteikent staet. Ende als alle die manier van kyesinghe, inleydinghe ende confirmacie mitten ghebeden is geschiet, so comen al die susteren weder in dio camer ende vernyewen haer obedienci den ghecoren priorinne in teghenwoerdicheit der visitierres ende des rectoers. Finde als si seit tot een ygheliken, beghinende van den outsten; love ghi ghehoersamheit na sinte Augustyns reghel? antwoert si:

7. Ic love dat. Mer die donaten loven simpel ghehoersambeit. Als dit ghedaan is, staet die priorinne op ende knyelende voer den rectoer lovet si hem ghehoersambeit voer haer ende voer haer huus in deser forme: Ic suster $\mathrm{N}$ love ghehoersamheit u vader rectoer van desen onsen huse ut bereel onses generaels capittels voer mi ende voer desen huse. Desghelije sel si mede doen als men enen nyewen rectoer inleydet in teghenwoerdicheit der vaderen ende alle des convents. Alle dien dach sellen die susteren overbrenghen mit vrolicheit en si sellen tweewerf eten, ten waer een botvast ${ }^{1}$ ) ingheset van der heiligher kercken ${ }^{2}$ ).

Van dien daghe voert sijn alle die susteren sculdich der priorinne ghehoersam te wesen als haer moeder, gheliker wijs als si ghehouden sijn haren rectoer ghehoersam te wesen als goede kind(eren) Goods haren gheesteliken vader. Die priorinne, die nyewe ghecoren is, sel haer professi mit enen openen brief, bezeghelt met haer dienstzeghel, den naesten generael capittel doen in desen formen: Ic suster $N$. ${ }^{3}$ ).

Hierom ist dat men buten consent des generaels capittels of des ousten prioers der visitierres ende des meesten deels alle der nonnen die priorinne van haren dienst niet setten en sel. Ist dat enighe priorinnen, die ghecoren is, in een ander haus

1) Bot $=$ geboden. Hier dus een geboden vastendag.

2) Hierna een drietal regels in het Hs. opengelaten.

3) In het Hs. twee regels opengelaten. 
enighe erfnisse of besterfnisse aancoemt, die wijl dat si daer is, dat sel gaen totten huse daer si professijt is.

Van die priorinne ende hoe si haer hebben sel nae dat si ghecoren is. Dat vijfte capittel.

Naedat die priorinne gecoren is en van die susteren ontran$7 \mathrm{v}^{\mathrm{o}}$. ghen, sel si voertan van hem allen in eeren ende reverencie ghehouden worden, soedat een yghelic voer haer ghaende een weynich haer toe nighen sel. In wat stede enighe susteren sitten buten den convent, utghenomen die werchuse, ist dat die priorinne daer coemt, so sellen si opstaen ende. niet weder sitten, thent si sittet of die andere niet sitten; mer gaet si voer hem, so sellen si opstaen ende haer toe nighen ende staende bliven thent si voerbi ghegaen is. Gaet si midden doert convent, hetsi int choer of in den reventer so sellen si alleen een luttel nyghen. In den capittel, als si gaet int middel ran den convent, daer sellen si opstaen ende staende bliven thent si sittet. Soe wat suster haer als si sittet een boec of wat anders voerleit of ghevet, die sel haer nighen. Die susteren sellen daertoe sien dat si bovenal voer haer in allen haren habijt ende zeden hem stichtelic hebben, noch teghens haer en murmureren opdat si ran God niet gheslaghen en worden als Oza, die die arck des Heren rechten woude; of mit Maria Moyses suster ende mitten kinderen van Israhel die teghens Moyses murmureerden. Ende soe wie van haer berispet wort, sel vluchts oetmoedelic op haer knyen verghiffenis bidden. Wederomme sel die priorinne hem allen een spieghel ende een exempel der zedicheit wesen. Haer cledinghe ende beddinghe ende sel noch in verve, noch in costelicheit, noch in ghedaente verscelen van den habijt der ander susteren. Si sel pinen ${ }^{1}$ ) haer medesusteren te regeeren in vrede ende eendrachticheit. Si sel onrustighe berispen; die cleyn8. moedighe troosten, ende verduldich wesen tot hem allen ende dat boven haer craften is sel si den rectoer andraghen dat te corrigieren ende alle dinc bi sinen rade sacken (sic) ${ }^{2}$ ) ende ordinieren. Si sel pinen te wesen in den choer onder die ghetiden, ende dat capittel der ghebreken te minesten eens ter weke des vridaghes te houden en sel si niet laten. Si bewaert in den choer haer weke gelike die ander ende si hout die eerste stede in den rechter choer. In die meerre dubbelde hoochtiden

1) Zich beviijtigen.

2) Waarschijnlijk $n^{\text {sachen" }}=$ in orde brengen, bezorgen. 
ende daer boven doet si alle den dienst, utghenomen die metten ende beide die resperen, die die rectoer bewaert. In die prijm ende compleet seit si Confiteor ende nae die ghetide Fidelium ende Adjutorium ende nae die compleet gheeft si die benedictie. Nae compleet sel si pinen silencium te houden. Want haer niet en betaemt als ander susteren tot swighen ende rust hem gheven, dat si haer keren sel tot ydele callinghen. Si sel daer oec toesien dat si niet lichtelic en spreken in steden die ordiniert sijn te swighen. In den reventer sel si mitten anderen susteren, ende als die andere eten en daer mitten ouden susteren bi die scelle sitten, ten waer dat haer crancheit of siecte anders eysschede. Der priorinnen behoert die weldaden ende aelmissen den convents te kundighen ende ghebeden te bevelen. Haer behoert oec die $d$ walinghen der susteren die lesen in den choer of in den reventer of oec in den capittel te corrigieren, of dat enen anderen te bevelen. Die priorinnen ende rectoer, ghemeen

8 vo. of bisonder, ende sellen niement ontranghen ter oerden, noch enighe brieve onder des convents name beseghelen of enich lant of erve boven tien iaer verhueren, of dat convent tot enighe ewighe laste brenghen buten consent der capittularen, welke behalve die rectoer ende die priorinne twintich wesen sellen, mit welcken twintich si altoes des convents saken, aenneminge des personen, vercopinc of vervreemdinc der landen of erren, of daer men des convents seghel toe behoeft mede sluten sellen. In andere daghelixe saken moghen si terreden wesen met die suppriorinne ende die procuratrix. Si sellen nochtan wachten, dat si mit costelicheit des timmerts of mit sculde dat convent alsoe niet en beswaren, dat hem enich noot doet daerom lande of renten te vercopen. Waert dat enighe suster van den capitularen teghen den rectoer of der priorinnen, of teghen dat meeste deel des convents haer sin of eens anders kijllic haer vermetede te bescermen, of die des capittel heymelike saken onder dat convente brochte ende dat van ghewoente dede, ende daerof vermaent niet of en liete, dese sel men als een verstoerster des vreden van den ghemenen capittel utsluten, nochtan hier en boven sel men se corrigieren mit swaerre correctie welke penitenci gheset wordt in goetduncken des overste na die mate des sculdes ende wesen of ghestante desgheens die daer sculdich is. Die priorinne sel somwilen die werchuse visitieren om die susteren to troosten ende pinen alle weghe

9. Frede ende eendrachticheit te maken. Si sel oec op heilighe 
daghe na middach of des avonts die susteren te samen roepen om mit hem minliken te spreken van den doechden ende ghebreken ende van die observancien der oerden. Die priorinne sel iaerlics twee of driewerf of also dicke alst haer goetduncken sel alle der susteren bedden, kisten ende cleynoden mit naersticheit doersoeken, opdat die motte des ejghenheits ${ }^{1}$ ) die heylighe religie niet en verderve. Ende die susteren en sellen niet laten te toenen al dat si bi hem hebben, opdat si niet en vallen in die vervaerlike sentenci des doots mit Ananyas ende met Saphira; aendenckende dat die na(ar) den gheesteliken rechten niet waerdich en sijn op een kerckhof begraven te worden. Si sel mede ondersoeken mit die vesteryewaert wat een yghelic noot is, ende dat bescriven ende die procuratrix sel dan een yghelic besorghen als dat dient nadat des huses goede vermoghen. Gheen suster en sel yement enighe brieven of gave senden of gheven; noch van jemant ontfanghen of eysschen buten oerlof des rectoers of der priorinne. Ende is dat sy jet ontfanghet, so sel si die persoen nomen ende die brieven toenen. Die hier teghen dede sel men nae die reghel dienich oerdelen. Die cleyne diensten moghen die rectoer ende die priorinne scicken bi rade der suppriorinne ende des procuratirs. Goede(ren) die to bewaren ghebrocht worden hetsy in ghelde of in anderen dinghen, sellen weten mitten rectoer, die priorinne, suppriorinne ende die procuratrix. Mer ten is niement gheoerloft dese voerseide goede(ren) ut te lenen, to vercopen of te verwandelen buten consent dergheenre die se te bewaren gebrocht hebben.

9 vo: Ghiften in goude, silver of ghelde ende enighe ander goede(ren) van waen si comen, sellen van desen vieren totten ghemenen oerbaer des huses ghescicket worden ende van desen, als ran alle den anderen sel die procuratrix in die iaerlixe rekeninc voer dat convent bewisinghe doen. Die ghelde die tot des procuratrixs officien niet en horen, of enighe andere costelike dinghen sel men sluten in des convents kist. Gheen priorinne en sel utlenen of ontranghen an ghelde teffens of ghedeilt boven rijf rijnsse gulden buten weten des rectoers. Ist dat haer noot is yet ut te gheren, dat sel uten ghemenen goede(ren) nemen ende die procuratrix sel daerof als van den anderen rekeninghe doen. Gheen priorinne of convent en sellen borch worden voer enigher waerliker lude sculde buten consent

1) De verkeerdheid van het hebben van eigendom. 
des ousten prioers. Die brieven die den convent gheseynt worden en sel si niet opdoen, mer si sel se den rectoer brenghen om op to doen in tegenwoerdicheit van haer, der suppriorinne en der procuratixs. Die priorinne ende die susteren, noch $0 e c$ die rectoer en sellen onder hem niet ontfanghen enich testament te vervolghen buten oerlof des ousten prioers. Gheen priorinne, alwaert oec bi die wille des convents, en sel haer selven of dat huus verbinden buten weten ende rade der rectoers, anders sel die priorinne die hierteghen doet ende die nonne die dat consentieren van die visitierres swaerlic ghecorrigiert werden. Die priorinne sel den rectoer alle dinc te kennen-gheven ende niet buten sinen rade te handen trecken ${ }^{1}$ ). Voert meerre sel si ghelijc die rectoer mit die suppriorinne ende procuratrix een 10. slotel van des convents kist ende seghel bewaren, welke kist men setten sel buten den dormiter in een openbaer stede nae ordinancie der visitierres ende alle die brieven die men seghelen sel mit des convents seghel sel men scriven mit die naem des rectoers, der priorinnen ende des convents.

Van die suppriorinne. VI capittel.

Die suppriorinne sel gheordineert worden van den rectoer ende den priorinne bi rade van de capitularen, die men haer bevoelen daer of horen sel. Ende als si gheordineert is, sel si in den lufter ${ }^{2}$ ) choer die eerste wesen. Ende wanneer die priorinne niet bi den convente en is, so sel si haer stede in allen bewaren ende dan en lest si niet, noch en dient ten reventer; mer ist dattet haer weke is, so sel si een ander scicken die haer stede vervult. In den anderen dinghen sel si haer hebben als ander susteren. Als men die priorinne lichtelic vinden mach soe en hoert die suppriorinne niet toe yement oerlof te gheren yet te doen of te laten, mer als men die priorinne niet lichtelic vinde of te spraec en mach comen, soe mach die suppriorinne in cleyne dinghen oerlof gheren die niet en moghen beyden. Der suppriorinne hoert sonderlinc toe in dien dinghen daer die priorinne in berispelic in is of versumende die si selven mercket, of die haer van anderen susteren te kennen ghegheren werden te rermanen, of den rectoer te kennen gheven, dat hi si vermaent ende nochtan altoes voer die ander susteren also veel

1) Ter hant trecken $=$ zich bezighouden, ter hand nemen.

2) Lachter = linker. Het Maria-koor is steeds rechts van het altaar, links dus van den toeschou wer. 
als si mach te ontsculdigen. Anders en sel nyement vermeten van der priorinne afterspraec to doen of bi haer selven te beris10 . pen. Men mach nochtant wel den suppriorinne te kennen gheren isser yet dat in haer te berispen is. Ist dat si dicwijl vermaent haer niet en betert soe en sel men se nochtan onder die ghemeente des convents niet berispen, mer men selt opt openbare den rectoer of den visitierers of den ouste prior ende sien dattet ghebetert wort. Die suppriorinne selle alle iaer als men visitiert, ghelijc dat oec doet die priorinne, absoluci bidden van haren dienst. Nochtan mach se die rectoer mitter priorinnen op ander tiden alst hem goetduncket of setten bi rade des ghesontsten 1) deels van den cappitularen. Waert als die priorinne van den convent, waer dat dan oec die sappriorinne gheboerde van daen te wesen so sel die ebdomedaria segghen Fidelium, Confiteor ende Admitorum ende gheeft die benedicie ende doet ander dinghen die totten dienst Goods horen.

Van die procuratrix van dat PII capittel.

Die procuratrix sel van den nonnen gheordineert worden, van den rectoer ende der priorinne bi rade des ghesontsten deels van den capitularen. Dese sel truwelic die sorghe der dinghen van buten draghen ende niet groots noch njewes doen buten rade des rectoers ende der priorinne of yet groots gheven buten haren oerlof. Als dat si ontfanghet of utghevet sel si mit naerstigher sorchvoudich(ei)t scriven. Alle die susteren die wat bevolen is, die sellen haer toevlucht tot haer hebben van des si behoeven, ende die susteren die somtijt jet onredelic van haer begheren en sel si niet onwaerdelic bedracken, mer mit oetmoedighen woerden in rechter rreedsamh(ei)t weygheren. Si en sel gheen gelt utlenen of yements ghelt of goet in bewarinc nemen buten weten des rectoers ende der priorinne, noch si en

11. sel haer niet vermeten voer yements sculde borch te worden. $\mathrm{Si}$ en sel niet laten also reel als si mach oude sculde des cloesters to betalen. Haer hoert toe alle die renten ende winninc ${ }^{2}$ ) des cloesters van waen dat si comen, op seker tiden te manen ende te ontfanghen ende weder als dat eysschet ut te gheren. Die procuratrix en sel binnen den helen iaer teffens noch allenken om Goodswil enich aelmisse gheren an ghelde boven die

1) Ghesont $=$ onbeschadigd. Hier dus het onbeschadigste deel $=$ de meerderheid der capitularen.

2) Wininghe $=$ winst.

vI. 
waerde van enen rijnsse gulden, ten waer bi oerlof des rectoers ende der priorinnen. In anderen aelmissen en sel si boven die ghemeen mate niet gaen buten oerlof van hem beiden.

Gheen suster en is gheoerloft gelt bi haer te hebben, ende die rectoer of die priorinne en sel oec nyement oerlof gheven ghelt bi hem te hebben, utghenomen die procuratrix. Als die enighe dienste hebben van haers dienstweghen, enich ghelt onfanghen, dat en sellen si niet langhe bi hem houden, maer die procuratrix alset dient overgheven. Gheen suster en sel oec hebben screen of kist of yet dat men mit een slotel sluut, utghenomen die procuratrix ende diegheen die dat van haerre officien weghen noot is; ende daer sel die priorinne een slotel of hebben. Siet of hoert die procuratrix jet van der lekensusteren ongheordenierlic geschien, dat behoert haer toe alst tijt is oetmoedelic te berispen, of der priorinne ist noot te kennen te gheren, ende die berispt wort sel oetmoedelic haer scout spreken. Die procuratrix sel altoes bereit wesen rekeninc to doen van alle dat haer bevolen is also dicke als haer die rectoer ende die priorinne

11 vo. des vermanen ende si en sel niet versumen mit hem dicwijl to spreken van den state des huus ende der familien. Si sel eens des iaers voer die tyt des generaels capittels of voer die risitaci van al dat si utghegheren of ontfanghen heeft, dat si sculdich is ende dat men sculdich is roer dat convent, een ghemeen rekeninc doen, ende daerna bidden, dat men haer den dienst verdraghen. Nochtan macht si die rectoer ende die priorinne op ander tide van haren dienst setten bi rade des ghesontsten deels des convents. Alle die ander officialen, utghenomen die suppriorinne en is gheen noot voert convent openbaerlic om verlatenis 1) te bidden, mer die rectoer ende die priorinne mit die suppriorinne ende die procuratrix hebben die aen-ende of te setten alst hem goet duncket. Si sel besorghen dat niet min dan twee besette susteren en sellen reysen in die marcten buitens lants om laken te vercopen of te copen ende dat bi oerlof des ousten prioers; nochtan raden wi meer, dat men die laken binnenlants vercopen om vresen die daar ingheleghen sijn. Ende al ist dat die procuratrix als Martha in veel dinghen sorchroudich ende verbaest moet wesen, nochtan en sal si dat silencium ende inkeren haers selfs niet altemael verwerpen, mer alsoe veel alst die saken des huus verhenghen, sel si haer selven

1) Kwijtschelding, vergiffenis. 
pinen of te trecken om haer inwendighe oefeninc waer te nemen, opdat si lesende, denckende ende biddende die onrustighe beroeringhe haers ghemoets, die ut sorghe ende besackinc der dinghen van buten opstaen, besact worden ende dat si in

12. der arcke haerre borsten jet salichs mach sluten, welcke si somwijl den lekensusteren mach utrispen 1). Ende ist sake dat God verbieden, dat si versumende, utstortende of wederstribbich ghevonden wort, ende dicwijl daerof vermaent haer niet en betert, so sel men een ander in haer stede setten ende laten haer selfs waernemen, opdat si haers selfs salicheit doch wercke, die ander menschen salicheit niet en con wercken.

Tan die kelrewaert dat PIIJ capittel.

Die officie der kelrewaersters sel men enen ghetruwen suster bevelen. Dese sel dicwijl omtrent den coken en de kelre wesen, opdat si daer broot ende bier, butter ende vleysch ende ander dinghen, die in den kelre sijn, bewaren mach. Oec sel si sorchvoudich wesen, dat men dat broot te tide backen ende dat bier te tide brouwen ende datten susteren gheen moynisse daerof en worde, noch den huse scade. Nochtan van die manier te backen ende te brouwen en hoert tot haren dienst niet mer des procuratrix. Desen betaemt temael goedertieren ende lijdsam te wesen, opdat si niet alleen der susteren crancheit mit medeliden verdraghen, maer oec haer quaetheit liden can ende sonder murmureren den susteren dienen ende te moete gaen. Gheen suster en sel gaen in die kelre of in die coken sonder oerlof, utghenomen die priorinne. die procuratrix, die kelrewaert ende oec die siecwaert als sijs behoeret om der sieken wille. Dese kelrewaerster sel dienen tot verlichtenis des procuratrixs ende tot haer sel si in alle dinghen toevlucht hebben.

Van die reventerwaert IX capittel.

Die officie van den reventer beveelt men een van de susteren.

12 vo. Dese behoert toe op ghesette tiden als des middachs ende des aronts die tafel te bereiden, broot ende bier daerop te setten, water oec in die waterraten te ghieten; die tafellaken, dwalen ende die kannen die men in de reventer besicht te bewaren; die kannen dicwijl te wasschen of te doen wasschen. Si sel oec voersien dat die tafellaken ende handtdwalen, hetsi in den reventer of bi dat watervat, als noot is, vernieuwet worden.

1) Utrispen = uitspringen. Hier dus de beteekenis van mede laten gevoelen, mededeeling des harten. 
Si sel mede besorghen kandelaers die men des winters in den reventer den susteren des avonts voerset als si eten; die men alsoe scicken sel dat tween of drien een lichte mach dienen. Elke suster, nae ordinancie van den ionghesten beghinnende, sel mit die reventerwaert die spise an te draghen ende of te nemen, haer weke houden, ende als men vast dranc an te dienen totter collacien. Mer van den sonnendach voer vastelavont tot paesschen toe in te lesen ende te dienen volghen si malcander alle daghen. Mer is die vergaderinc der susteren-meerre so mach men een of twee daertoe soecken mede te helpen ende te dienen. Ende waert die reventerwaert dicker ende langher gehindert wort so mach si haer maeltijt volbrenghen alst convent mitter gracien wechgaet. Si sel oec als die sext ut is of die noen nader tijt of nader vesper als men des avonts eten sel, als die spise bereit is, dat erste teiken ten eten doen alst tijt is. Als men tweewerf eten sel, sel men altoes dat teiken doen te tien uren, ende des aronts te viven. Mer als men vast dat teiken totten middachmael to elf uren ende des avonts totter collacien to

13. ses uren. Voert so vermanen wi den susteren dat si scuven to rraghen of te ondersoeken wat men coken sel, noch gheen suster en sel wedersegghen die spise die ghemeenlic hem alleen bereit is, dan overmits dwanc der ziecten; want het en betaemt niet onser professien om spise of dranc te murmureren sonderlinc, want onse reghel seit: Temmet $u$ vleisch mit vasten ende mit onttrecken der spisen alsoe veel als $u$ vermoghen verhenghet. Ist dat enighe suster dergheenre die dienen merckelike confuse onder die maeltijt doet, als dat si een scotel of kanne brake of stortede of dierghelijc, die sel voer die priorinne tafel comen ende haer scult spreke op haer knyen staende, thent si van d' priorinnen een teiken neemt op te staen. Mer is dat yemant van dieghene die daer sitten desghelijc versumen, die sellen vluchts naedat die susteren opghestaen sijn haer scout kennen ende Venia bidden. Die reventerwaert is oec noot te weten der susteren $\operatorname{cranch}(e i) t$ dien si wat sonderlincs bi der priorinnen of des siecwaerts raet gheven moet, opdat si weten mach wat si enen Jghelic gheven sel. Si sel oec roersien, dat datselve dat men den susteren voersettet ghelijc, sonder utnemen der personen, ghedeilt worde, ten waer oft die priorinne goet dochte, dat men enighe om haer crancheit of siecte meer of wat anders soude gheven. Onder den eten sel si dicwijl ommesien of yemant ghebrake, dat sijt vervollen mochte, ende 
sonderlinc op der priorinnen of si yet woude. Ist dat si enighe suster siet luttel of niet eten van dat haer voergheset wort, dat sel si der priorinnen te kennen gheven. Voer die sieke 13 vo. susteren sel si sorchroudich wesen ende na groetheit of cleijnheit der ziecten sel si alsoe veel als si mach hem besorghen ende daer si mitte wercken niet en mach sel si haren goeden wille mit blide aensichte ende minlike woerden toenen. Als si voer dat rechtreynster ${ }^{1}$ ) staet soe en sel niet veel ende overvloedighe woerde spreken, mer si sellen stille ende binnen monts segghen dat noot is. Als men eet ende collaci drinckt sel si voerhoeden dat gheen gheruft of stemme ghehoert en worde dan alleen des leesters. Haer behoert oec toe als men die susteren sceren of laten sel die vaten ende warm water ende al dat daertoe behoort te bereiden ende na der sceringhe of latinghe elc bisonder weder te hemelen ${ }^{2}$ ), ten waer dat die priorinne een ander hadde bevolen. Ende haer behoert toe des winters also dicke alst noot is, vuer te maken den convente in den stede daertoe bescict, als na der missen, voer dat middachmael, voert avontmael of voer die collacie of oec alst seer kout is, vluchts na prijm of tercie of anders alset noot is. Nochtant mach die priorinne dat een ander berelen.

Van die siecwaert dat $X$ sapittel.

Die sorghen van den sieken sel men enen van den susteren bevelen, die dat een yghelic noot is van der kelrewaert of van die procuratrix sel eysschen. Dese betaemt sonderlinghe ontfermheitich ende mededoghende to wesen. Men sel die sieken vermanen dat si na sinte Benedictus reghel gheen overvloedighe ende onmoghelike dinghen en begehren ende dat si dieghene die hem dienen met murmuracien niet en bedrucken mer dat si des goeden opsets dat si anghenomen hebben ghedachtich sijn 14. ende ghelijc als ghesonde van ghesonde so sellen onse sieke sielen van waerlike sieken. Men sel oec nauw wachten dat die sieke susteren van haren diensteren niet vergheten en worden, sonderlinghe die te bedden leghen, want alsoe sel men haerre sorghe draghen, dat si haestelic ghenesen moghen. Die siecwaert, alle tijt alst nut ende noot is, mach mitten siecken of mitten anderen spreken van der zieken behoef ende ut die ghetide

1) Rechtveynster = aanrechtvenster waardoor de gerechten worden aangegeven.

2) Opredderen, in orde brengen. 
bliven, desghelijc mede die ziecken. Si sel oec boecken besorghen om die ghetide te lesen ende die heilighe lessen te studeren, ende alst noot is bi haer selver mitten zieken te lesen of te doen lesen. Dese mach te helpe hebben een suster die haer in den dienst der sieken onder dienen mach, die bi den zieken stadelic bliven sel noch uten siechuis buten weten der siecwaert yet langhe merren $\left.{ }^{1}\right)$. Haer behoert toe, als die quellinc beghint swaerre te worden, dat der priorinnen te kundigen, opdat si tghemeen ghebet laet doen voer die zieke. Haer behoert mede toe te besorghen die dinghen, die noot daertee sijn om die zieken te monighen ${ }^{2}$ ) ende te olyen. Ende als enighe die doot naket haestelic mit veel slaghen die ratel te slaen, die baer ende die cleder die men daerop leit ende anders dat men totter gravinghe behoeft te besorghen ende na der begravinghe alle dinghen op te hemelen. Als die sieken in den siechuis langhe bliven ende hem gheen noot en is overmits haerre siecten dicwijl te spreken, so sellen si dese reghel hebben: Van compleet tot des morghens nae die prijm ende onder die ghetiden sellen si silen-

14 vo. tium houden, ten waer of si somwijl mitter siecwaert of mit haer ghesellen van haer noottruft spraken. Die sieken, die niet to bedde en legghen, moghen spreken onder maeltijt van goeden materie ende scriften. Die ghebeden, die den convente bevolen worden, sel die siecwaert den sieken te kennen gheren. Ende ist sake dat si hem in enighe dingen ontgaen, dat en sel die siecwaert niet laten hem te vermanen, ende ist dat sijt niet en beteren der priorinuen te kennen te gheren ende waert noot dat haer verkeertheit van der priorinne in den capittel voer alle die susteren berispet worde. Ende ist dat si alsoe haer niet en betert also verre als haer crancheit dat verhenghet, sel men si corrigieren na den regheliker disciplinen. Als die siecwaert duncket gheen noot te wesen den siecken dat si langher bliven in die infirmarie so sel syt der priorinne te kennen gheren dat si weder comen totten convente ende totten ghemeynen observacien. Mer ist dat si dan noch meerren goedertierenheit behoeven, dat wort ghelaten inder priorinne besceidenheit dat si hem besorghe of die siecmaert bereel te besorghen als si enen yerghelic noot siet te wesen. Mer als daer sulcke sieken niet en sijn, daer haer noot is becommert mede to wesen,

1) Toeven, uitblijven.

2) Mugnighen $=$ het H. Sacrament des Altaars toedienen. 
so sel si haer oerde houden als ander susteren van den cloester. Gheen suster en sel totten sieken ingaen ende mit hem spreken sond' oerlof, utghenomen die priorinne, die procuratrix ende dio siecwaert ende dieghene die den sieken dienen.

Van die vesteriewaert dat IX capittel.

Totten dienst der vestiarien behoert na den reghel alle clederen der susteren, wollen ende linnen, pelsen ende scoen bi die pro15. curatrix te besorghen ende alsoe die te versonnen ${ }^{1}$ ) ende verscudden, dat si niet ghequetset en worden van den motten. Dese suster sel pinen na vermoghen des huus een yghelic minlic te gheven dat hem noot is. Mer dieghene diemet ghevet, sellen hem hoeden, dat si niet overvloedichs en eysschen ende die dinghen die men hem gheret sellen si bewaren sonder verderven. Ende dat willen wi enen yghelic vermanen, dattet in gheenre manieren en betaemt gheestelike susteren enich cleet om snootheit te versmaden, ten waer dat openbaer onghemac anders yet dwonghen te eysschen. Want dat men om snootheit verwerpet is verdoemelike hoverdi, mer dat men verwandelt overmits onghemac is verdraechlike crancheit. Die susteren en sellen oec noch clederen, noch yet merckelijes onderlinghe wandelen of wisselen buten die vesteriewaert bi goetduncken der priorinnen, mer si sel een ygheliken na betamelicheit des tijts ander gheren ende ander wedernemen ende bewaren. Si sel daer naerstelic toesien, dat men gheen curiosicheit en ghebruke als men die clederen snijt. Want alle die glorie des conincs dochter is ran binnen ende niet van buten. Der susteren hemden ende slapellaken sellen wesen van groven doec, welke om crancheit der naturen men henghet linnen te wesen, desghelijc om dieselve sake worden hem in den dormiter bedden van plumen ghegunnet. Gheen suster en vermeet haar te legghen sonder hemde, doec ende wijl. Si en sellen oec niet baden dan hoeneer ende nut

15 vo. wien die priorinne als noot is hem dat oerloft. Tot haer clederen nemen si twee overrocken ende twee onderrocken, een swarte mantel, een pels, twee subtilen, twee hemden of meer, een caproen dies hebben te doen; kousen, socken, doeken ende wilen nae dattet noot is. Tot die (wilen) en sellen si niet meer nemon dan drie spelden ende tot die doeken drie. Desghelijc mede die conversinnen ende donaten. Soe wat totter susteren beddinghe of de cledinghe behoert en sel niet achten, ondersaet of prelaet,

1) Aan het zonlicht blootstellen. 
van wat grof heit het si, mer alleen dat die coude mach verdreven worden ende die naectheit bedecket. Want sekerlike tot allen gheesteliken susteren behoert oetmoedigheit ende snootheit 1) der lakenen ende tot allen dinghen die si ghebruken behoert snootheit, armoede ende verwerpenheit. Die mantelen en caproens sellen daerom sijn van swarten ende groven laken ende mit gheenre ander verwe vermenghet; mer die rocken ende kousen sellen wesen van witten laken. Welke laken so costelic wesen mach dat twee utgerecte ellen van den swarten ende drie van den witten die waerde van een Vrancrijcse scilt niet merkelic boven ende gae, ten waer dat die breetheit des lakens meer eysschede. Die kousen ende socken sellen wesen van groven laken. Die mantelen sellen corter wesen dan die rocken omtrent een hantbreet, ondervoedert mit witten laken ende si sellen boven hebben een of twee grove knopen. Die onderrocken ende pelsen sellen voer wesen mit knopen totten gordel toe ende die mouwen van haer onderrocken sellen wesen mit drie of mit vier knopen. Die overrock sel men also te maten lanc

16. maken dat si niet ontamelic ${ }^{2}$ ) en sweym ${ }^{3}$ ) opter aerden ende sonder knopen, mer bi twee of drie vingheren breet sel sy scelen van d' aerde. Die subtilen sellen twee hantbreet corter wesen dan die overrock ende beneden ghelike ront. Die pelsen sellen wesen van scapen of lammeren vellen. Alle die scoen der susteren sellen wesen van swart coyen of scapen leer, ende voer niet scarp, opdat sy die voeten overmits engheit niet en wringhen ende men sel se boren te samen binden mit riemen. Der susteren riemen of gordelen sellen wesen van simpelen lere ende niet ghever wet(?) ende si sellen niet boven een duum breet wesen. Ende in den gordelen of messen ende in allen haren dinghen die si ghebruken int ghemeen of bisonder en sel niet wesen van side, gout of silver of van anderen dinghen die costelic sijn of curiose schinen, utghenomen den dienste des altaers. Soe wie hierthegen doet, die sel men dat dinc nemen ende nae goetduncken des overste scarpelike corrigieren. Ende om dit te ondersoeken sel die priorinne doen als hiervoer in den capittel van der priorinne bescreven is. Ist dat jement gheseint wort enich cleet of mes of anders yet suld dat sel

1) Geringheid.

2) Onbetamelijkheid.

3) Zweven. Hier dus slepen. 
men van goeder ghewoente niet denghenen diet gheseint is mer billiker een ander suster gheven, nochtant laet ment in des overstes goetduncken of sijt ghevet diet gheseint is of een ander.

Tan die sacrista XIJ capittel.

Die sacrista neemt die slotelen van die rectoer of van die priorinne ende mitten slotelen die bewaringhe alre dinghen die in de kercke sijn: alven, casuffelen, boecken die totten dienst Goods horen ende alle ander dinghen sel si ontfanghen in ghe-

16 vo. tale ende in een cedel teykenen. Ende die dinghen die onder haer bewaringhe ghehouden worden sel oec die priorinne in een cedel gheteikent hebben, opdat si weten mach, waer si reden voer eysschen sel alst noot is. Si sel alle die dinghen die onder haer bewaringhe sijn naarstelic bewaren ende dicwijl toesien of erghent yet ghebreect of verdorven wort. Ist dat oec yet van de clederen of van anderen dinghen die totten dienst Goods horen ghescoert of versleten is of in enigher manier weder te maken of te versien is, daer sel si sorch voerdraghen dattet hoeftelic weder ghemaect worden. Alle dinghen sel sij reijn bewaren ende datter onreijn is, sel si besorghen dattet ghowasschen worde ende naerstelic hoeden dat die ghewiede clederen, nadat si veroudet sijn tot gheenre tijt vertoghen en worden ut den dienste Goods tot anderen dinghen to besighen. Si sel oec die asch, als si yet van ghewiden dinghen ghebrant heeft, storten op ghewide steden. Die corporalen sellen van node ghemaect worden van dat alre puerste ende reynste linnen ende in laden of reyne sacgens naerstelic te samen ghevoudet bewaert worden. Also dicke als die corporalen te wasschen ende die doecges daermede die kelcken ende der priesteren vingheren na der abluci mede droghet, die sellen ghewasschen worden van een priester of $\operatorname{van}$ een dyaken in een reyn vat dat daertoe gheordiniert is, ende ghieten dat eerste water daer hi se in ghewasschen heeft ind' piscinen ende die ander wateren in een reyn stede. Mer want die sacrista van alle dinghen die totten dienst Goods horen, als van den ghewiden vaten ende orna-

17. menten, van de missalen ende anders datter toe behoert, gheen daghelixe sorghen ende toesien hebben en can, omdat si besloten is, soe worttet bevolen des rectoers ghesellen, dat hi die dinghen bewaer. Die waskaersen, oly totter lampe ende ander dinghen die noot sijn sel hi van die procuratrix eysschen. Die ornamenten die men wasschen of weder maken of nayen moet sel hi haer reyken; die heilighe oly omtrent paesschen procureren, ende 
die kelcken en sel hi niet vergeten to wasschen. Totten dienst der sacristen behoert oec oly ende was totten lichten der kercken; als si die niet en heeft van die procuratrix te eijsschen ende te bewaren; die lampen des dormiters te besorghen ende die clocke te smeren; waskaersen ende andere kaersen also dicke alst noot is selven te maken of van ander susteren maken laten ende alse ghemaect sijn een van den buten susteren utgheven. Ende si sel daer toesien dat si inder kercken dat ghetal der waskaersen of die grootheit boven onse ghewoente of sonder noot niet en vermeerret, mer die manier die nae ghescreven staet pinen te houden. In den meesten hoochtiden totten vesperen ende metten ende ter meestermissen ${ }^{1}$ ) sel men setten vier waskaersen. In meerre dnbbelde feesten ende in dubbelde feesten ter vesperen ende metten ende totter meestermisse ende ghemeenlic in alle convents missen sel men setten twee waskaersen opten altaer. In hoochtiden van neghen lessen ende binnen der octare van paesschen ende pinxteren ende als men houdet ghedenckenisse van onser vrouwe te resperen ende te metten sel men slechts een waskaers setten int midden des altaers. Elke kaerse en sel niet wesen boven dat

17 vo. ghewicht van enen ponde, utghenommen die paeschkaers, welke niet en sel gaen boven dat ghewicht van vijf ponden. In den kercwyinghe ter vesperen, ter metten ende ter meestermissen worden onsteken twalef waskaersen an den wanden der kercken. Mer in des altaers kermise ende in die principael hoechteijt des patroens desselven altaers ter vesperen ende ter metten worden ghesettet een waskaers ende totter missen desselren altaers twee. Des cloesters principael patroen sel men hoochlic vieren, mit feestelike octaven. Kolen totten wiroec inder missen ende inder vesperen ende in den winter tot der dienres hande te warmen en der priesteren die misse doen ende andere dinghen die noot sijn tot ten dienste des altaers, sel besorghen des rectoers gheselle bi hem selven of bi een ander. Op die hoochtijt des gheboorten ons Heren totter eerster vesper ende tot die compleet sel die sacriste die ghewoenlike tijt te luyen een ure voercomme. Si reghet oec dat cloester na ghewoente mit hulpe der susteren ten minsten tweewerf des iaers, mer dat choer mach si dicker veghen alst noot is; mer die kerc buten den sloten besorghet een van den buten susterren dat si ghe-

1) Hoogmissen. 
veghet wort ende ten sel gheensins gheschien doer die besloten susteren, welken alle utganc in den gheesteliken rechten verboden is. Tot haer behoert oec des daechs ende des nachts behoerlike tiden te bewaren om den dienst Goods te doen ende die teikenen te luden. Ende van paesschen tot heilich Cruus

18. Exaltatio, beide die daghen daer in besloten, als die gracie ut is of die noen na der tijt die susteren te wrecken na den slaep als een ure gheleden is. Men sel totter metten, totten ghetide dat roer die misse gaet, te resper ende compleet tweewerf luden. Dat eerste teiken ter vesper luud men te drie uren; mer als men vighelie (sic) van neghen lessen lesen sal, luud men een ure vroegher; als men lesen sal van drie lessen een half ure eer. Tusschen den tween teykenen ter tercien of ter sexten na der tijt, ende ter vesperen toeft men bi een half ure, mer te metten bi een quartier. Totter metten als men lesen sel, luud men altijt ten halven voer vier uren ende die prijm ende tercie nae die tijt leest men an die metten. Mer als si metten singhen luud men te elf uren ende na der metten een wijl tijts gheleden, lesen si prijm ende tercie na der tijt, utghenomen die paesch ende pinxterweke die men dan singhet. In die nacht der gheboerte ons Heren luud men ter metten te halven voer die elfte ure ende nae den eten ghift men den susteren middachslaep ende desghelijc oec een palmdaghe. Vander hoechmis te doen, of ander dat men voer of nae leset of singhet, sel men die teikenen also matighen, dat als men niet en vast alle dinghen in de kercke te tien uren gheeyndigdet sijn; ende als men vast to elven, mer naer die sonnendach in quadragesima een half ure later. Die tijt te luden drie daghen voer paesschen is int ordinarius utghesproken. Fnde aldaer sel men des donredachs ende

18 vo. des saterdaghes dat teiken der metten doen ten halven voer drie uren, mer des Goeden Vridachs te twalef uren. Totter compleet, als men lesen sel, doet men dat eerste teiken to seven uren ende dat anderde ten halven voer acht uren, mer als men singhet voercomt men die teikenen een half ure.

Van die cantrix XIIJ capittel.

Totten dienst van die cantrix behoert alle tijt die dinghen die inder tafelen te teikenen sijn te tide te scriven. Mer totten dinghen die men van tween susteren te samen singhen sel, als si bequaemlic mach, sel si pinen te ordineren susteren die malcander gheliken in haer singhen. Ende ist dat si enighe susteren inder tafelen, nadat si ghesien is, verwandelt heeft, dat 
sel si den susteren die si ghewandeld heeft te tide te kennen gheven. Ende is daer yemant die niet volbrenghen en kan of en mach daer si toe gheteikent is, dat sel si die cantrix to weten doen, dat si daertoe een ander ordiniert. Die susteren die wat singhen of lesen sellen inder kercken, die sellen dat te voren oversien, ist dat si des behoeven of men sel si corrigieren. Ist dat daer yemant buten den choer blivet, die in de tafelen gheset sijn, so behoert die cantrix in singhen of in lesen haer stede te vervullen of een ander to bevelen. Ist dat in de sanc der kercken yet ghedwaalt of ghetwivelt wort ende in rerheffinc of nedersettinc des sancs, daer en sel haer niement in berechten; ende wat si eerst beghinnet dat en sal nyemant anders beghinnende verstoren, utghenommen die priorinne. Ende ist datter oec haestelik enighe dinghen te singhen of te

19. lesen opcomen, die niement sonderlinghe to voren gheset en sijn, die mach si dan doen singhen of lesen die si wil. Haer behoert oec den susteren die ter tafel lesen, te wisen wat ende wanneer dat si lesen sellen, ten waer dat die priorinne om saken willen een anderen dat berael. Die omelyen der heiligen in hoochtiden, ende op sulke daghen die eyghen omeleyen hebben, sel men alre eerst lesen, mer des saterdaghes leest men altoes die reghel, ten waer dat men se om enigher hoochtijt wille of om een ander wittelike sake voerlase. Als die omelye ghelesen is, so leest men van den feesten ende tiden dat daer bi sonder te lesen is. Totter cantrix behoert hoeneer dat men overmits enighe saken in den salmen ${ }^{1}$ ) of in den sanc of in enighe anderen dienste Goods meer dan ghewoenlic is haesten of vertrecken sel, dat si dat den susteren te weten doen sel. Ende als meer dant behoerlic is haestet, of den dienst Goods vertrecket, so sel si dat totten rechter mate temperen. Is dat si in haren dienst yet versumeliken doet, so en sel men se niet vermetelike berispen van enigher suster, mer men selt haer in den capittel vermanen. Die cantrix sel oec sorchvoudich wesen, dat alles middelmaete ghehouden worde in den sanghe, opdat hi lude oetmoedighe swaerheit ende die devocie verwrecke. Die cantrix behoert te vermanen die susteren die al te verlanc of al te haestelic die sanc of psalmodio segghen. Ende een suster sel altoes wesen cantrix ende succentrix in elken choer.

1) Psalmen. 
Dan die ebdomedaria XIIIJ capittel.

Die ordinancie van die ebdomedaria beghint van den outsten, 19 vo. ende van elke weke wordet ghewandelt van dat een choer in dat ander. Mer is dat ghetal der weecwaersteren ongelijc so coemt den dienst des ebdomedari vander laetster totter priorinne, al waer si oec in dat selver choer. Is dat sake dat die ebdomedaria sommels van den choer blijft, so sel die iongher die daer naest staet haer stede vervullen. Mer als si siec is of anders becommert is, dat si van alle die weke luttel of niet doen en mach, so sel dieghene die nae haer volghet haer boert bewaren, welke si weder omme haer boert bewaren sel, ist dat si so haestelic weder ghesont wort of weder commet totter convente. Ende dat wi vander ebdomedaria des choers gheseit hebben, dat 'sel men oec houden van den anderen weecwaersteren.

Van der doden na der doot. Dat XV capittel.

Nae der octave van dertienendach ende van Pinxteren doen wi een ghemeen beghanghenisse ${ }^{1}$ ) der doden, sonderlinc onser broederen, susteren, ouderen ende vrienden. Ende men singhet righeli (sic) van neghen lessen nedes ende des anderen daghes misse voer die doden. Desghelijc mede opten vierden sonnendach na Paesschen voer die doden, die in den generael capittel opghelesen sijn, mer die vigheli (sic) sel men lesen. Als yemants sterfdach van den broederen ende susteren van onsen cappittel ghekundicht wort, sel men lesen vigeli (sic) van neghen lessen Parce Michi ende singhen missen ende men sal voersien dattet gheschie als men eerst mach. Ist dat men die misse niet singhen en mach, so sel men die misse bisonder lesen ende men sel een collect segghen in des convents misse. Een yghelic priester sel een misse voer hem lesen ende men sel

20. een dertichste houden, ende die gheen priesteren en sijn sellen eens bisonders vigheli (sic) van neghen lessen. Desghelijc alle die susteren al ist dat si in den choer ghelesen hebben, nochtan sellen si voer die misse een vigheli (sic) van neghen lessen bisonder lesen ende die niet te choer en gaen tweewerf bisonder. Mer die gheen vigheli (sic) en konnen, sellen twowerf lesen vijftich $\mathrm{P}$ (ate)r $\mathrm{N}$ (oste)r en an elke $\mathrm{Pr}$. Nr. Requiem eternae. In haer eyghen conventen daer si professijt sijn, leest men die souter te choer ende men singhet righelic (sic) van neghen lessen Parce Michi als men eerst mach ende men sel een

1) Nagedachtenis. 
tricenarium houden ende een Jghelic priester sel voer hem drie missen lesen, behalve die hem in dat tricenarium boeren ${ }^{1}$ ) to doen. Die clercken die gheen priesters en sijn ende die nonnen sellen een souter bisonder lesen, mer die die souter niet en konnen, sellen lesen hondert ende vijftich Pr. Nr. mit Requiem Eternae. Ende die clercken, priesteren ende nonnen sellen binnen die eerste maent lesen vijfwerf die seven psalmen mit Req(ui)em Eternae sonder letanien (sic). Mer die niet lesen en konnen sellen vijfwerf vijf en twintich Pr. Nr. mit Requiem Eternae lesen. In die eerste maent leest men int choor driewerf ter weke vigheli (sic) van drie lessen nedes ende -driewerf ter weke seit men een collect ter hoechmisse, als des manendaechs, des woensdaechs ende des vridaechs, ten waer of daer duplex festum of daerboven, of een feestelike octare tusschen quaem, soe soud men die vigheli (sic) bisonder lesen, mer die collect ter missen mach men wel segghen, behalven die meerre dub-

$20 \mathrm{r}^{\circ}$. belde feesten ende daerboven ende die weke nae Palmen. Ende in die eerste maent sellen alle die susteren driewerf ter weke op dieselve daghen disciplijn ontfanghen. Ende alle dat iaer lanc, als men vigheli (sic) seit, leest men een collect voer hem ende alle iaer op haer iaerghetide leest men vigheli (sic) van neghen lessen Parce Michi ende men singet misse in den convente. Den conversinnen ende donatinnen doet men dat selver, naedat men den nonnen doet, mer men en leest voer hem gheen souter int choer. Die priorinne sel oec den convente van onse capittel bi enen sekeren bode, als si eerste mach, des susters doot kundighen op de peyn van twee rijnsse gulden, nochtan sel si in die naeste vergaderinc der vaderen mit meerre strengheit der discipline oft noot waer ghecorrigiert worden.

Van die armaria $X P I$ capittel.

Die armaria, dat is die boeckbewaerster, heeft alle die boecken des cloesters die totten dienst Goods niet en horen in haerre hoede, welke si oec bisonder gheteikent sel hebben mit haer eyghen namen, ende elkes iaers utlegghen ende verluchten ende naerstelik mercken of daer yet van den motten ghegheten of anders ghescoert of verdorven is. Endo also dicke als si den susteren noot sijn sonder murmuracien der susteren to gheven. Si sel alle boecken teikenen voer of after mit des con-

1) Te beurt vallen. 
rents name ende die boecken, die se buten huus ntleent, teikenen wi si se leent ende hoe langhe ende op tide weder eysschen opdat si niet verloren en worden. Als men den vreemden die 21. men niet en kennet leent, dat sel si teikenen ende nemen een pant van hem, ist dattet den rectoer of priorinnen goetduncket. Die priorinne sel oec alle die boecken, die die armaria te bewaren heeft, in enen brief gheteikent hebben, opdat si weten mach waervan si reden eysschen sel alst noot is. Die boecken des Oudes ende Nyewes testaments of die boecken daer men den dienst Goods mede doet en sel niemant vermeten te corrigieren sonder des ghemeens capittels raet, dan ut anderen boecken onser husen die ghecorrigiert sijn, ten waer datter na des rectoers goetduncken of der besceydenre broederen openbaer dwalinghe scheen. Desgheliken ende willen wi die ghemeen ghewoente onser husen in den accente van gheenre suster verwandelt hebben. Ende ist dat in der leerres der heiligher kerckenboecken enighe lochenachtighe dinghen of die noot sijn verbetert schinen, dat sellen die rectoers besorghen, also veel als si moghen, dat si na correcten boecken onser husen of men se crighen mach corrigiert worden. Hier eyndet dat eerste deel der insettinghe.

Hier beghinnen die capittelen vander anderde distinctie. Van der onfanghinghe ende cledinghe der novicen $\mathrm{I}$.

Van insettinghen der novicen IJ.

Van der professien IIJ.

Hoe hem die susteren hebben sellen onder den ghetiden $\mathrm{IIJ}$. Hoe hem die susteren hebben sellen onder des convents misse $\nabla$.

Tan die tijt te studeren $\mathrm{vI}$.

Van den capittel der sculden $\mathrm{VIS}$.

Van silencium Vus.

Van den arbeit der handen $\mathrm{Ix}$.

Tan die spreecstede $\mathrm{x}$.

21 vo. Hoe die sloten ende vensteren ende sciven sellen wesen $\mathrm{xI}$.

$\nabla$ an den inganc in den slote $\mathrm{xJJ}$.

Van den dormiter xurs.

Tan den reventer xums.

Tan dat vasten $\mathrm{xr}$.

Tan der collacie ende dranc $\mathrm{XVI}$. 
Van der biecht ende communicieren xvIJ.

Van scheren XiIJ.

Van laten xax.

$\nabla$ an die conversinnen $\mathrm{xx}$.

Hoe si hem hebben sellen in den dienst Goods ende van haer ghetiden $\mathrm{xxI}$.

$\nabla$ an die donatinnen xxrs.

Van lichte scult xxirJ.

Van middelbaer scult xxmr.

Van swaer scult xxr.

Van swaerre scult XXVI.

Van alre stoaerste scult XXVis.

Van verlopen susteren $\mathrm{xxVIIJ}$

Hier beghint die anderde distinctie. $\nabla$ an der ontfanghinghe ende cledinghe der novicen. Dat eerste capittel.

In te ontfanghen ende te insetten der novicien sien wij dat grote behoetheit ende naersticheit te doen is, omdat dicwijl die quade, die gheen berispinghe en liden ende mitten goeden ghemenghet worden, sware moynisse der gheestelicheit in te

22. brenghen pleghen ende die goede, als die naedat si ontfanghen sijn sonder onderwijs of leringhe ghelaten worden, groten hinder in den voertganc der waerachtigher religien te liden pleghen. Het wort strenghelike verboden den rectoeren, priorinnen ende conventen der nonnen, dat si voort meer teghens des paues verbodt niet meer tot susteren aen en nemen, dan van des cloesters goederen moghen sonder ghebrec van goede ghehouden worden. Ende ist dat si daerteghen doen, so sel sulke ontfanghinghe niet wesen ende nochtan sellen si swaerlike van den vaderen ghecorrigiert worden. Dat ghetal van tsestich nonnen 1) en sel men in een huus niet boven gaen sonder oerlof des generaels capittels. Mer die donatinnen, binnen of buten, moghen also veel wesen als den huus noot sijn. Buten dat slot moghen si hebben twee of drie priesteren, behalve den rectoer ende alsoe veel ghesins als daer noot is. Om alle dieghene die daer comen om ontfanghen te worden so willen wij, dat dese besceidenheit ende sorchvoudicheit ghehouden worde datter

1) In 1462 werd bij brief van 3 Mei van het kapittel aan het convent toegestaan het getal tot 200 zusters en 10 conventualen uit te breiden. Zie mijn Foorm. Amst. Prouwenkloosters, Bijdr. B. v. H., Deel XXII, blz. 249. 
gheen suster aenghenomen worden om grootheit haers gheslachtes, noch om rijckheit, noch om gaven, noch om enich ander dinc dat totter hoverdien des werelts of tot ghiericheit hoert. Welker gheselscap overmits quetselicheit haerre wanzeden, of overmits moynisse of quellinghe dergheenre, die tot haer gheselcap of maescap horen den anderen susteren die in der oerden sijn scadelic of verderffelik of scadelic mochto 22 vo. werden. Mer in den susteren die aen te nemen sijn, vermanen wij dat men so mercken sel of si goede zeden hebben ende sonderlinghe of sy fastmoedichs et (sic) (en) goet haers om megaens sijn ende niet onlijdsam in haerre correctien. Noch geen buus en sel hem vermeten enighe nonnen of enighe persoen, die ontfanghen is ter proevinc of ter professien in enighe buse van onser oerden of van enighe ander oerden, an te nemen buten consent der vaderen van onsen capittel. Noch men sel boven drie paer susteren in een huus ter oerden niet ontfanghen, noch die moeder mitter dochter dan bi oerlof derselven vaderen, als oec die driedeel des convents dat begheren. Ende waert dat also dat enighe ontfanghen worden, soe en sel die laetste gheen stemme hebben in den capittel, tensi haer ghegheven bi den vaderen. Die vreemden die gheen proefelike ghetuuch mit hem en brenghen en sellen si niet ontfanghen totten habijt eer si een half iaer gheproeft sijn, ten waer dattet den rectoer, der priorinnen mitten capittelaren eendrachteliken, of den drien delen van hem goetdochte, dat men meer daer mede soude haesten. In welke tijt si te proeven sijn of si volstandich sijn in hare opset ende die hoverdie der werelt volkomelike versaken; overmits of verwerpinghe der waerliker clederen; overmits oefeninghen des arbeits ende der oetmoedicheden; overmits bereide ghehoersambeit tot allen harden ende scarpen dinghen; overmits stervinghe haers willes ende haers eygenssinnes; overmits bewarinc des swighens ende des rustes; overmits stadicheit

23. in heilighe lessen te lesen ende in bede; overmits danckelike ontfanghinghe der berispinghe ende der correctien; overmits wackerheit in wakinghe ende abstinencien; orermits bereitheit haer sonden te biechten ende te openbaren haer becoringhen ende overmits alle andere dierghelike in welken men proeven mach of si waerachteliker der werelt ende hem selve sterven, ende Gode in voertganc der heiligher religien leven willen. Sie en sellen niet aennemen binnen den slote maechden dio haer twalef iaer noch niet vervult en hebben; noch totten

VI. 
habijt der religien also langhe als si haer vijftiende iaer niet en ghenaken buten oerlof des capittels. Van den novicia en moet men niet eysschen noch cleet, noch anders yet, opdat dieghene die eysschede niet en vallen in die sentencie des bannes. Die priorinne sel verliesen haer priorinscap ende die procuratrixe haer dienst ist dattet bi haren weten tot werc is ghecomen. Als dan den susteren behaghet van enighe an te nemen totten habijt, so sel men haer voerlegghen hoe die reghel ende die statuter te houden sijn, opdat si weten mach onder welke insettinghe ende gheboden si haer bughen sal. Ende ist dat si mit gheenre anxt der strengheit van haren opset ofghekeert en mach worden, so sel men se, alst der priorinnen goetduncket, vermanen van een van de susteren to bidden om ontfanghen te worden totten habijt. Ende dan sel si op enen ghesetten dach comen in den capittel ende nedervallen voer den rectoer ende den convent. Als si dan van den rectoer ghevraecht

23 vo. wort, wat is dyn begheerte, so sel si also legghende antwoerden: Ic begheer die ontfermhticheit Goods ende uwe medesusterscap. Dan sel si bi bereel des rectoers staen op haer knyen ende men sel haer vraghen voer hem allen of si ut enigher oerden is ghegaen, of si vry is, of si enighe man trouwe ghelooft heeft of si verbonden is mit enigher gheloften ende of si enighe heymelike ziecte onder haer lede heeft, die niet nezelic en is, of si van beclachten of sculde voldaen heeft, of si erighe andere hinderen heeft om welke het gheen oerbaer en waer dat men se aennaem. Ende als si dan elken gheantwoert heeft, so sel die rectoer in den eersten haer voerlegghen die strengheit der oerden ende wat moynissen ende becoringhen si in der oerden liden moet in verbiedinghe haerre eyghen wille ende ghehoersambeit te volghen. Hoe strenghelike alle observancie der reghelen van denghenen gheeysschet sel worden die se loven, ende hoe scarpelike die versummende ende wederspannich sijn, gheoerdeelt worden ende die ander dinghen die in den oerden swaerste ende scarpste sijn sel hi haer segghen ende rraghen of si tot allen desen om haer salicheit bereit is dat si voer hem allen haer wille openbaert. Ende ist, dat si dan onvervaert blivende antwoert, dat si overmits betruwen in alleen die goedertierentheit Goods ende den susteren ghebeden dese dinghen naedat die godlike goedertierentheit verleent volbrenghen sel, dan sel weder segghen die rectoer: Die Heer moet die gheren 24. alle dese dinghen te volbrenghen, opdat u totten ewigen leven 
mogheste comen. Ende dat convent antwoert Amen. Dan sel si voer der priorinnen voeten neder knielen ende haer handen te samen legghen in den handen der priorinnen. Ende die priorinne sel segghen: Van Goods weghen ende onser ontfanghen wi di ende gheren onse gheselscap. Dan sel die rectoer voer hem allen tughen nemen, dat ghelik als si haer vriheit houden ut te gaen, desghelijc mede houdet dat convent haer vriheit ut te setten, of, dat God verbieden moet, haer conversaci hem niet en behaghede ende dan sel die rectoer haer een dach setten daer men se op cleden sel, ende men seit haer, dat si haer bescacke dat Heilighe Sacramente ontfanghen. Hier en binnen sel sy haer, naedat si vermach, ontreiden van sculden ende ander saken die noot en nut sijn ghedaen. Als dan die dach naket, so sel men se vermanen van een van de susteren, dat si den rectoer van al haren voerleden leven haer biechte doe, ist dat sijt niet ghedaen en heeft. In den daghen dat men se cleden sel, als dat ghetide ut is dat men houdet voer die missen ende die priester mitten heilighen clederen staet voer den altaer, so sel die suster die men cleden sel voer den grade des altaers comen ende knyelen ende daer sel men haer, als dat manuael inhout, haer cleder, die si binnen plech te dragen, uttrecken ende dat habijt der religien weder antrecken. Die novicia wort anghedaen een subtijl sonder mouwen alle die tijt dat si novicia

24 vo. is ende si houdet die laetste stede. Dat officium die versikelen te singhen, bewaert si in haer choer ende ist datter meer is so bewaert een yghelic sijn weke. Dese cledinghe sel geschien op enen werkendach sonder enighe feeste mer die professi sel ghe. schion op enen heilighen dach nochtan sonder hoverdie of grote costelicheit. Noch men sel enichsins toelaten werscappen 1) voer die cledinc, als die susteren buten den slote spreken mit haren ouders ende vrienden, noch mede voer die professie. Die dat henghen sel men van de visitierres scarpelic corrigieren, nochtan sellen si mede in den generael capittel mit meerre strengheit ghepinicht worden.

Van insettinghe der novicen IJ capittel.

Als die novicia ghecleet is, so sel si haer dinghen geheel der priorinnen gheven, ist dat sij se heeft, ende niet si selver mer die priorinne of die sij beveelt sel die dinghen bewaren. Van welken dinghen wanneer, of wien, of hoe die novicia voer

1) Werscap $=$ Gastmaal. 
haar profesia ordinieren wil, dat sel si vrilike moghen doen. Nochtan hebben wi een loeflike ghewoent, dat si dat vluchts als si int cloester coemt overgheret in der priorinnen handen. Men sel se bevelen een van de susteren die goet ghetuucht heeft, dat si se naersteliken lere hoe si haer hebben sel in nighen, in gaen, in staen, ende in al haer ghelaet, hoe dat si sel hebben nedergheslaghen ende behoed $\theta$ oghen, stilleken ende niet haestelike spreken, ende in allen zeden een teiken der oetmoedicheit tonen. Si sel oec haer leeren lesen ende singhen hogher ende

25. lagher nadat die tiden eysschen; ende dat si int openbaer doen sel, dat sel si voer haer meerstersse eerst int heimelike proeven ende wennen. Si sel haer oec leren hoe si totten priorinnen ende totten anderen susteren spreken ende reverencie tonen sel. Mer sonderlinghe sel si haer dicwijl vermanen dat si hair waerlike zeden ende ghewoenten int beter pine te verwandelen ende die quade di si ghedaen heeft pine te biechten ende te bescreyen, oec die ghebreken ende vleyschelike begheerten, te verdrucken haren eighen wille ende goetduncken om dat goet der ghehoersambeit to sterven, ende alle oetmoedighe ende verwerpen dinghen ende alle arbeit gaern aen te vaten. Ende aldus sel si den ouden mensch uttrecken mit sinen wercken, ende voertan die doechden volghende worden een nyewe mensch in Christo. Ende opdat si dat te volcomeliker mach vercrighen so en sel si, als diegheen die der werelt doot is ende haer selve, haer van ghenen dinghen van buten of van saken des huses in enigher wijs onderwinden heimelic of openbaer, alleen Gode begherend te leven als een besorchde behoedster haerre consciencien. Si sel scuwen lawe ledicheit ende haer pinen te veronledighen mit heilige lessen, mit ghebeden, met grondighen beweghen des herten, mit heilighe ghedachten ende mit arbeit hairre handen na ghemeenre wisen, also alst haer berolen wort. Of te leren die dinghen die tot die ghemene insettinghe ende tot waerachtighen religien ende tot gheesteliken roertganc

$25 \mathrm{vo}$. behoren haer ghemoede toe te gheren ende te wennen bi rade ende leere haere meestersse. Ende opdat si haer te bet mach raden, so sel si baer meestersse al haer swaricheit ende al haer conversaci dicwijl openbaren. Si en sel haer selven niet bieden mitten anderen susteren te spreken of van haren wercken te onderwinden, mer hem alle eer bewisende en sel nauwe yet voer den anderen dorven spreken ende tottien dat men haer vraghet, sel si mit scaemte ende anxte oetmoedeliken ende mit luttel 
woerden leren antwoerden. Totten ghemenen convente, daer si mede wesen moet ende sonderlinghe in den dienste Goods, sel si des daghes ende des nachts mit alre wackerheit ende vuricheit des gheest wennen derotelic ende te tide te comen. Haer meestersse sel oec haer daghelixe wanderinghe dicwijl aenmercken of si jet min off meer doet dan noot is, opdat si se heymelic mach berispen en se onderwisen alst noot is. Ende wanneer si haer in enighen dinghen ontgaet, daer men se om in den capittel besculdighen soude, daer sel se haer meestersse om berispen ende alst in den capittel ghewoentlic is sel si voir haer knielende of legghende haer Venia doen bidden. Somwilen sel si haer oec venia doen bidden voor elke suster ende sonderlinghe voer den outsten ende begheren help haers ghebeden om haerre beteringe ende stantachticheit. En is datter meer is, so sel si somtijt mit hem capittel houden ende wisen hem, hoo si van den ghebreken malcander besculdighen sellen, ende die

26. besculdicht worden haer venia bidden, opdat sie wennen die oerde te houden ende die versummenisse te verhoeden. Men sel oec gheenre novicien professi ontfanghen eer een iaer verrullet is buten oerlof des generaels capittels of des outsten priors. Hier en binnen en sel men haer ghenen dienst berelen. Die susteren sellen hem wachten, dat si niet en spreken mit die novicien van ydelen ende waerliken dinghen of van haer oude leven. Oec en sellen si hem niet te kennen gheven van den staet des huys of van die ghebreke der personen of van enighen anderen dinghen; die dat dede soude swaerlic ghecorrigiert worden. Die priorinne en sel gheen novicie oerlof gheren te spreken mit luden van buten, si of een besochte suster en si daer teghenwoerdich, sonderlinghe daer men voer ducht vrese des wedertreckinge ter werelt. Die novicien die sterven voer haer professie, gheeft men moghelic dat selve na haerre doot, dat men denghenen doet die gheprofessijt sijn, utghenomen dat men se niet en scriven in den kalender sonder merckelike sake. Ende denghenen oec die sterven eer si ghecleet worden gheeft men dat selver, mer den souter en leest men niet van dat verbant ${ }^{1}$ ).

Van der professien. Capittel IIJ.

Als die tijt aenstaet dat die novicia gheconsecreert sel worden,

1) Verbant $=$ verbintenis. In het middeleeuwsch HS. van het klooster te Bethlehem staat ${ }_{n}$ scholde"; in het latijnsche HS. uit Albergen ${ }_{n}$ psalterium ex debito non legitur". 
ist dat si ontfanclic scijnt ende in ontfermherticheit te bidden stadich is, so sel men se alst den rectoer ende der priorinnen goetduncket in den capittel laten roepen. In welke capittel als si

26 vo. nederlegghende oetmoedelic ontfermherticheit begheert, so gheeft men haer haren vryen wille wech te gaen of si wil, ende al haer dinghen hoe ende wye si wil te deylen. Ende ist dat si volherdet cloppende, so gheeft men haer consent als si begheert ende men sel haar segghen dat si haer bereit totten Heilighen Sacrament ende haer profesi mit haer selfs hant scrive. Mer ist dat si niet scriven en can so sel si enen anderen bidden diese haer scrive, nochtan sel si mit haer selfs hänt daer een teyken des cruses onderscriven. Ende in der missen naedat Offertorium sel si voer den grade des altaers nederlegghen ende daer sellen die clederen haerre professien, die men benedien sel, bi haer legghen. Alle andere dinghen die men doen sel, sijn ghescreven int manuael. Die forme der professien is dese: Ic suster $\mathrm{N}$ love voer God ende allen Heilighen in teghenwoerdichit des prioers ende onses rectoers stantachicheit in desen cloester; ewighe reynicheit des lichaems; derven eyghens goets ende ghehoersamheit onser priorinnen ende haer rechte naecomelinghen na sinte Augustijns reghel ende ghemeen insettinghe ons generaels capittels.

Dieghene die professi ghedaen hebben sellen in den convent die stede houden, die een Jghelic dien dach dat si ghewijt sijn ghegheren heeft, ten waer dat den oversten prioer om saken wille van enighen anders goetdochte of ten waer dat die rectoer ende die priorinne enighe om saken wille een wyl tijts lagher setteden. Nochtan en sel ghene professide susteren stemme

27. in den capittel hebben tensi dat si haer vijf ende twintichste iaer naket noch si en sel niet eer in den choer ebdomedaria wesen, ten waer dat men om ghebrec der personen den rectoer ende der priorinnen anders goetdochte.

Hoe hem die susteren hebben sellen onder die ghetiden. Dat IIIJ capittel.

Alle die nonnen sellen te samen onder die ghetiden ende des convents misse wesen, utghenomen die om siecte of crancheit daer niet en wesen en moghen. Mer dieghene die gheset sijn tot enighe wercken of diensten, die en sellen niet uten choer bliven sonder oerlof, utghenomen die procuratrix. Ende ist dat si overmits sake of node gheen oerlof en moghen bidden, dat selve sellen si in den cappittel to kennen gheren ende renia bidden. 
Als men dat teyken doet ter kerc te gaen so sellen die susteren, waer dat si sijn, allo dinghen laten ende te choer haesten. Ende van die tijt dat men enighe ghetide van den daghen beghinnet, thent dattet al ut is, dat men doen sal en sel niement uten choer gaen, si en heeft eerst oerlof ghenomen ende als si dat ghedaen heeft daer si om ut ghinc sel si weder comen. Onder $\mathrm{Te}$ Deum, Benedictus, Magnificat ende Nunc dimittis ende in der misse onder die collecten, epistel ende Angeli, Prefaci, Sanctus, ende Agnus Dei, ten waer dat nootsake dwonghe, sellen si sonderlinc scuven uten choer te gaen. Des morgens dan, als men dat teyken doet, sellen si wackerlic opstaen ende hem cleden ende bi haren bedden rustelic bliven, ten waer

27 vo. dat hem die noot $\mathrm{dwonghe}$ ut te gaen, ende haer herten bereiden mit goede ghedachten of ghebeden totter heiligher wakinghen, tot dat men dat leste teiken doet ende dan sellen si devoteliken toe ten bedehuus gaen. Als si in der kercken comen, so sellen si totten altaer laghe nighen ende voertgaen tot haren stoelen ende staen mitten aensichte ten altaer ghekeert, thent men dat luden aflaet ende dan nighen si totten knyen toe of knyelen voer die form ${ }^{1}$ ) nadat die tijt eysschet ende lesen Pr. Nr. Also langhe als si singhen of knyelen so sellen si hem hoeden van allen gheruchten ende in die kerc te comen of doer dat choer te gaen sellen si scuwen. Ende oft gheriel als si in die kerc comen of utgaen dat men seide Gl(ori)a $\mathrm{P}$ (at)ri of Gl(ori)a van den (h)ymmen of collect, so sellen si vluchts nighen. Dioghene die laet comet ter metten nadattet Invitatorium beghonnen is of totten cleynen ghetiden onder die (h)ymmen, die sel tot sijn stoel gaen ende sijn knyen een luttel bughen ende opter formen mit een cussen venia nemen. Ende ist dat yement coemt als die (h)ymmen totter metten begonnen is of oec tot allen ghetiden als die eerste psalm begonnen is die en sel sonder oerlof niet ingaen ende sel oec opter formen mit een kussen venia nemen. Ende al ist dat na der reghel die susteren al sulke zeden overal houden sellen dat niet geschien en sel in allen haren ghelate daer hem yemant anstoten mach, nochtan sel men dat naersteliker houden in den tempel Goods daer men

28. die godlike diensten doet. Daerom sellen si haer oghen alsoe houden ende bewaren sonderlinghe in der kercken ende in den

1) In het latijnsche HS. uit Albergen staat: Quamdiu ad genua vel supra formas inclinatur. Zie Arch. voor Nederl. Berkgesch. Dl. V, blz. 288 , 14 e regel. 
reventer, dat si hem selven gheen reescap der verstroynghe of der murmuracien en maken. Si sellen oec wennen haer handen tsamen te houden, ten waer of si wat houden souden of wat doen, ende alle haer andere leden betaemt hem van alle onsedicheit ende overvloedighe becommeringhen te bedwinghen, opdat si hem selven ende ander susteren van aendacht der psalmen ende ander dinghen die men in den dienst Goods oefent niet en verstroyen ende verletten. Die bladen oec omme te legghen of ander dinghen sonder noot over te sien, sel men scuwen, allermeest als men Pr. Nr. stilleken leset of als men enich lesse of collecte seit of yet anders. Daerom sellen si die cantrices ende ebdomedarien voer den godliken dienst voersien wesen, dat si dan gheen noot en hebben mit sulken dinghen hem te becommeren wanneer si hem selven ende ander susteren, overmits onrusticheit ende confuse, van inwendighe aendachte oftrecken moghen. Men sel oec daer toe een stede sacken (sic) (zoeken) in welke die susteren te samen comen sellen op een seker ure den dienst Goods over te sien, sonderlinghe teghen hoochtiden of als buten der ghewoenten enighe dinghe te doen of te singhen sijn, daer die priorinne, of die cantrix of een ander, die dat die priorinne beveelt, bij sel wesen. Als si een boec of een stoel of anders wat mit merckelic gheluut laten vallen sellen si opter formen mit een kussen venia nemen. Als si niet en 28 vo. nighen, als men nighen soude, dan bi vermaninghe van enen ander of anders dat si doen souden niet en deden, die sellen mitter hant op dat pariment venia nemen. Als si alleen dwalen in den convent, sellen si mitter hant op dat pariment renia nemen, mer als si ander mede doen dwalen so sellen si oec mede haer scout daerof in den capittel bekennen. Die wat alleen singhen of lesen ende dan dwalen, die en sellen niet vluchts, mer als sijt al ut hebben mitter hant op dat pariment venia nemen. Als dan in der metten dat $\mathrm{Pr}$. Nr. ut is, ende die priorinne een teyken doet, so sellen si hem oprechten ende keren hem totten altaer. Ende als Domine labia gheseit is ende men beghinnet Deus in adiutorium so teikenen si hem mitten teiken des cruses, daerna keren si hem te choer ende nighen tot Gloria Patri ende desghelije totten anderen ghetiden. In meerre dubbelde hoochtiden ende daer boven, sel men doen als in den capittel van den rectoer gheteikent staet. In feesten van neghen lessen ende daer beneden als men singhet, sel een suster alleen int choer daer die ebdomedaria is, singhen dat Venite, 
die versikelen, die responsen totten ghetiden ende dat vaers totter vesperen. Mer in dubbelden feesten singhen twee susteren dat vaers totter vesperen in dat choer daer die ebdomedaria is ende in meerre dubbelde feesten ende daerboven int middel van den choer. Mer ist dat men lesen sel, so sellen al dese

29. dinghen in dat choer, daer die ebdomedaria is, van die versicularia ghelesen worden ende die lessen van dieghene die lesen van elken drie ghelesen worden. Totter psalmen der ghetiden setten si, mer tot leste Gloria Patri sellen si op staen. Onder Ecce nunc benedicite staen si alle als men singhet. Die psalmen sel men besceidelic ende volcomelic singhen ende in dat middel des vaers een volcomen pause maken ende die laeste sillaba niet utrecken mer cortelic ofbiten, oec mede int leste des vaers. In den psalmen die men sonder sanc segghet, sel men int middel des vaers een corte pause maken. In der metten die susteren, die een lessen lesen sel of wat singhen sel int middel des choers, ist dat si van den nedersten is so sel si voer ende nae nighen an den grade des choers, is si van den bovensten so sel si int middel des choers nighen. Die wat te samen sellen singhen, die sellen te samen nighen an den grade. Die versicularia ontsteket dat licht totten lessen voer dat Pr. Nr. Die ionghen sellen die lessen lesen van die laetsten opclimmende ende elcs singhet dat vaers ran sijn lesse. Die ebdomedaria is en leset gheen lessen ten waer dat luttelheit der susteren dat eysschede. In dubbelden feesten singhet dat vaers mitter suster, die dat lesse ghelesen heeft, die bi haer boven staet in die meeste dubbelde feesten, ende daer boven singhen de outste die lessen ende die haer beneden naeste staet singhet mit haer dat vaers. Die susteren die dat eerste, dat vier le ende dat 29 ซo. sevende lesse lesen gaen voer dat lectrijn eer men dat $\mathrm{Pr}$. $\mathrm{Nr}$. beghinnet ende si en beghinnen dat lesse niet eer dat gherufte dergheenre die daar sitten stillen is. Als si die benedictie eysschet en hout si dat lichte niet in de hant, noch en keert die bladen niet omme, mer si ngghet totter benedictie. Die ebdomedaria en staet njet op om die benedictie te segghen, ten waer of men een evangelium lesen soude of dat die priorinne die benedictie eysschede. Opten daghen als men knielt, alsdan die leester die benedictie eysschet, staen si alle op mit die ebdomedaria, mer in der metten van den drien daghen voer Paesschen sellen si opstaen totter teiken der oversten. Totten lessen ende responsen sellen si alle sitten. In den feesten van 
neghen lessen ende daerboven ende binnen der octaven van Paesschen ende Pinxteren sel men luden tot Te Deum tot Patre Immense Maiestatis toe ende ist dat men gheen Te Deum en houdet so wederhael men dat respons ende dierwille luud men, ende die susteren sellen staen. In $\mathrm{T} e$ Deum tot Virginis uterum ende totten Bloede Christi ende tot die Gloriose Namen Ihesus ende Maria nyghen si dat hooft met reverencie ende tot die Godlike naem Ihesus, in welke alle knye wort gheboghen, sellen si mede een luttel haer knyen bughen. Ende ist dat si in den sanghen veel noten hebben, so nighen si in die vergaderinc van den Jaetsten sillaben. Totten versikel voer die Laudes keren

30. si hem totten altaer tot Gloria Patri toe. Totten laetsten vaersen van den (h)ymen ende tot Gloria Patri et Filio et Spiritui Sancto nighen si altoes totten knyen toe. Totten collecten oec in allen ghetiden als gheen tijt en is dat men knyelt, so sellen is desghelike nyghen. Mer isset knyelens tijt so knyelen si vluchts als men seit Kiri Eleison tot Per omnia secula seculorum van die eerste collect. Mer die ebdomedaria staet op ende leest die collect staende totten anderen collecten, ist datter enich naevolghen sellen si nighen. Als die metten ut is, leest men prijm ende tertie na die tijt. Tot dat Pr. Nr., tot Credo in Deum ende tot Confiteor in der primen ende compleet, alst gheen knielens tijt en is, so nyhen si in den convent totten knyen toe. Als die eerste collect van der primen ut is ende dat teiken ghedaen is, so gaen si van den ousten eerst totten capittelhuse, ende alst convent daer sittet, leest men van die maen ende die lesse ut dat marterilogium ende dan volghet Preciosa ende daernae als die collect Diriger ut is, leest men een lessen uten comment y) der regulen ende daeronder sit dat convent. Mer in den feesten van neghen lessen ende daerboven ende in den daghen van Paesschen ende Pinxteren leest men een pertikel van d' evangeli ende diewijl staet dat convent. Daerna leest men die iaerghetiden of sterfdaghe ist datter enighe sijn ende men ghedencket der doden mitten psalm De Profundis, versikel ende collect, ten waer dubbelde feesten ende onder die octave van Paesschen. Alsdan die priorinne gheseit heeft Requiescat in pace ende daerna Benedicite, is daer yet to segghen om beteringhe of voer den ghemenen oerbaer, 30 vo. dat mach si cortelic segghen daerna als dat capittel ghehouden is; ist anders capitteldach so volghen daerna die psalm Laudate

1) Comentario. 
Dominum omnes gentes ende die ebdomedaria seit dat versikel ende collect. Int eynde seit die priorinne Adiutorium. Ende ist dat men vast, so leest men sonder middel tercie. Ter vesperen, in den psalmen ende der collecten sel men doen als roer gheseit is in der metten. In die meerre dubbelde feesten ende daerboven beghinnet die rectoer ter vesperen Deus in adiutorium ende die antiffen op Magnificat ende thurificiert ${ }^{1}$ ) ende seit die collecten. Voer die compleet, als men des avonts eet, leest men die lessen Sorores ${ }^{2}$ ) sobrie estote, ende als dat ut is soe seit die priorinne Adiutorium. Daerna nighende of knyelende lesen si Pr. Nr. ende Confiteor. Als dat ut is keren si hem ten altaer ende die ebdomedaria beghinnet die compleet. Mer als men des avonts niet en eet, vluchts als dat luden ghelaten wort, so nighen si of knielen onder dat Pr. Nr. ende Confiteor. Na der compleet knielen si totter benedictien, thent een deel van de antiffen ghesonghen is ende men ontsteket lichten ter eeren van onser Vrouwen. Mer in die tiden van Paesschen nighen si totter benedictien. Als die antiffen mitten versikel ende collect ut is, soe sel men te love ende ter glorien der Jiaghet Marien driewerf cleppen ende een yghelic sel devotelic lesen driewerf Ave Maria. Daerna als dat teiken gedaen is gaen si opten dormiter die iongheste voer.

Hoe hem die susteren hebben sellen onder des convents misse. $\nabla$ (capittel).

31. Als men dat Introitus totter misse singhet soe staet dat een choer teghen dat ander. Mer als men singhet Salve Sancta Parens so knielen si tot Genua ${ }^{3}$ ) toe. Als die priester singhet Gloria in Excelsis, soe keren si hem ten altaer ende als die cantrix beghinnet Et in terra soe keren si hem totten choer. Tot Adoramus toe ende tot Suscipe deprecationem nostram nighen si totten knyen toe. Tot Dominus vobiscum keren si hem altoes totten altaer. Totten eerster collecten nighen si of si knielen, totten anderen collecten keren si hem ten altaer. In der missen van den vigilien der Heilighen, utghenomen die vigilien der Gheboerten ons Heren, dertiendach Paesschen, Ons Heren Hemelvaert ende Pinxteren, ende of men die missen van die vigilien op ten sonnendaghe songhe ende in den missen van den quater-

1) In latijnsch HS. net thurificat".

2) In het latijnsche HS. van Albergen staat: „Fratres".

3) Flectamus genua. 
temper sel men knyelen tot alle die collecten van der fery anders dan in den octaren van Pinxteren ende totter collect Deus qui tribus pueris. Als men oec des werckedaechs van den sonnendach of van der feri misse singhet, so knielen si altoes al waert oec dat men van der fery die ghetiden niet en hilde. Onder die Epistel, Graduael, Tractum ende All(eluy)a sitten si tot dat men All(eluy)a repetiert. Ist dat men Sequenci singhen sel, so staen si op bi dat eynde rant leste vaers. In de meerre dubbelde feesten ende daerboven singhen twee susteren dat All(eluy)a midden in den choer; mer in die tiden van Paesschen singhen si alleen dat anderde. Als men dat evangelium leset staen si

31 vo. ghekeert tot die dat leset, ende totten titel des evangelies teikenen si hem mit een teyken des cruses. Tot Gloria tibi Domine keren si hem totten altaer ende nighen laghe. Als men Credo beghinnet keren si hem totten altaer tot Patrem toe. Ende als men singhet Et Incarnatus est knielen si tot Et resurrexit. Onder dat offertorium sitten si. Als dat offertorium ut is staen si weder op ende keren hem totten altaer tot dat die Prefaci ut is. Als men Sanctus singhet keren si hem weder totten choer ende staen sonder lenen. Daerna legghen si neder tot dat ander Per omnia toe. In welker tijt si mit meerre naersticheit hem keren sellen tot devocien daer si sonderlinc vermaent worden mit groter aendachte des herten die weldaden onses Verlossers te ghedencken, daer si haer herten meest mede moghen ontsteken tot sijnre minne. Totter Elevacien des lichaems Christi ende sijns Heilighen Bloets sellen si recht op knielende mit aire reverencie aenbeden; mer tusschen der Elevacien sellen si neder legghen. Tot Agnus Dei staet dat choer tegen dat choer sonder lenen. Als dat ut is, so keren si hem ten altaer tot dat men die complende singhet; mer dat Communium singhen si choer tegen choer. Totten complenden nighen of knielen si als voergheseit is van den collecten. Mer in die vasten totter collect Super populum als men seit Humiliate capita vestra Deo so nighen si altoes. Totter Benedictien nighen si laghe choer tegens choer.

Van die tijt te studeren $\nabla I$ capittel.

Des heilighen daghes sellen die susteren pinen te studeren 32. ende die heilighe scrifte to lesen, omdat hem die tijt meer bequaem is ende si dan ledigher sijn dan op wercke daghe, in welke si hem totten arbeit haerre handen gheren moeten. Nochtan na onse reghel die seit: Dio boeken sellen op een seker ure 
alle daghe gheeysschet worden, sellen si des werckedaghes omtrent een half ure tusschen tween teykenen ter misse ende ter vesperen boeken om te studeren eysschen int ghemeen of bisonder, opdat si als si een luttel ghesmaket hebben van die gheestelike soeticheit bequaem moghen wesen in den dienste Goods. Mer buten die ure en moet niement studeren ende laten dat werc sijnre handen of den dienste Goods, opdat alle dinghen nae ordinancien in haer tijt geschien, utghenommen die ionghen, die behalven die tijt om te leren, haer sanc ende clergie een ure of meer na goetduncken des rectoers ende der priorinnen hebben moghen.

Tan den capittel der sculden VII.

Cappittel der sculden sel men houden vander priorinnen eens ter weke des vridaghes na die prijm of een ander tijt die daertoe dient, ten waer dat ment om enighe hoochtijt of om een wittelike sake vertoghen of voerquaem. Mer die rectoer sel eens ter maend capittel houden ende dan sel die priorinne als die susteren op haer knyen staen ende haer penitenci ontfanghen hebben, int openbaer oplesen van elk bisonder, hoeveel si in

32 vo. dier maent mit haer ghewonnen heeft. Als dan Benedicite gheseit is ende die susteren nedersitten mach die capittel hout cortelik segghen dat oerbaer gheseit is van die observancie der oerden ende correctie der susteren. Daerna vermaent men dat si voertcommen, die een nae den anderen, beghinnenden van den iongheste ende knielen voer den outste en spreken haer scout, dat men verstaen mach. Ende als si gheseit heeft, dat si in haer selven mercket, so bidt si den anderen of si yet in haer ghemercket hebben dat si dat vriliken om Goodswillen segghen. Eerst seit die ouste dat hi weet, daerna vermaent hi den anderen of si yet in die suster ghemercket hebben dat si dat vriliken om Goodswillen segghen. Ende dan mach een yghelic, beghinnenden van den outsten, segghen dat si van dier suster ghemerket hebben dat beterinc waerdich is. Ist dat een iongher yet seide ende een ouder nae ghedachte yet te vermanen, die en sel die suster niet weder roepen dan bi oerlof der outste. Die vermaninghe der sculden sel men doen oetmoedelic ende mit luttel ende simpelen woerden, die ghebreken niet verswarende, mer in minnen ende mit een mededoghende ghemoede simpelic segghende: onse suster heeft dit ghedaen of si heeft dat versuumt. Die anders doen of die ut passie vermanen sel die outste berispen. Noch die susteren en sellen niet verswighen 
of veynsen om yemants liefte of gunste, dat si die ghebreckeke sijn niet en vermanen of en besculdigen opdat si hem niet en besondighen teghen die reghel die daer seit: Des te meer en 33. sijt ghi niet onnosel is dat ghi u susteren, die ghi niet vermanen corrigieren moghet, al swighende laet vergaen.

Veel susteren en sellen een suster niet ghelic vermanen, mer eerwaerdelic die een na den ander. Daer sel men nauwe toesien in den capittel, dat die susteren niet lichtelic en spreken, ten waer of si hem selven of een ander besculdichde of die besculdicht sijn van den orersten ghehieten wort te spreken of ghevraghet wort of dat si van der ordinancie yet souden vraghen. Noch si en sellen tot malcander niet spreken, mer alleen tot die capittel hout. Noch gheen suster, die van den anderen besculdicht wort, en moet haer selven ontsculdighen, al waert dat si haer onsculdich kende, tensi dat si oerlof heeft van den outsten. Niemant en sel haer selven of yemant anders bescrermen of ontsculdigen in den capittel, tensi si hem dat van den outsten gheheten wort. Desghelijc en sel niemant buten oerlof des outsten in den selven capittel dien vermanen van die ghebreke, of andere van welke si van haer vermaent is; noch si en sellen malcander niet beroepen van heymelike ende biechtelike saken, mer alleen van dat openbaer is. Niemant en sel een suster besculdighen meer dan van tween of drien ghebreken; noch een suster en sel in een capittel niet besculdicht worden meer dan van drie of vier personen, ten waer oft den outsten anders goet dochte. Ist dat die besculdicht wort of berispet seer onlijdsamlic antwoert, dat sel men na goetduncken 33 vo. des outste een luttel tijts opsetten of terstont corrigieren. Als dat yement ut enighe ghetide, of dat hi hoert te wesen bi oerlof bleven, die sel als die andere daer sijt alle horen voer den outsten als si haer ghebreke gheseit heeft daaran segghen oec: mede en was ic niet tot dien ghetide mer bi oerlof bleef ic daerof. Die andere, die sonder oerlof daerof bliven, si sellen oec voer hem allen die sake segghen waerom dat si bleven, of der priorinnen, oft die sake eysschet, heymelic te kennen gheren. Noch si en sellen malcander ut suspicien niet beroepen, mer alleen dat si ghesien hebben of waerachtelic ghehoort hebben ende bewisen moghen. Want waert dat die beroepen dat missakede, ende die haer besculdicht heeft dat niet bewisen en mochte, so souden si die penitenci doen die diegheen verdient hadde, die si besculdicht heeft. Mer opdat die ghebreke niet 
verbercht en worden, moghen si den rectoer te kennen gheven dat si ghesien ende ghehoort hebben. Die suster, die daer besculdicht is, sel tot vermaninghe des outste nederlegghen ende bidden venia ende als si ghehieten wort op haer knjen te staen, ontfanghet si penitenci van den outsten ende gaet. Die penitenci sel men een yghelic setten van den outsten nadat die ghebreken ende die personen eysschen als hier na int eynde van den boeken ghescreven staet. Aldus dan sel men bisonder expedieren eerst die totter oerden ontfanghen sijn; die te samen sullen utgaen; dan die donatinnen; daeran die conversinnen; nae

34. die novicen of si daer sijn; daerna die nonnen die gheen capittularen sijn, ten laetsten die capittularen. Die saken die versproken sijn onder die capittularen sel men seer heimelic houden, noch men sel se buten den capittel yemant te kennen gheren. Ist dat yement ghevonden wort dat si enighe dinghen gheopenbaert heeft, die sel men uten capittel setten ende daerboven penitenci ontfanghen na grootheit des misdaets, ende sonderlinc ist datter enighe scandalisaci ut gheschiet is. Als alle dinghen in den capittel wittelic sijn gedaen leest men die psalm Laudate Dominum omnes gentes. Int eynde seit die overste Adiutorium ende alsoe sluut men dat capittel. Mer alremeest sel men dat wachten, dat nyemant buten dat capittel en spreket of en teikent van ghebreken of heymelike dinghen die men in den capittel verspreket, ende dat nyemant denghenen moylic si, die haer in den capittel vermaent heeft. Die hierteghen deden die soud men swaerlic corrigieren. Opten Goeden Vridach, des vridaechs voer Pinxten, opten Kersavont ende op Onser Vrouwe avont Assumptio ende als een suster van den huus ghesturven is, sellen alle die susteren, noonen, conversinnen ende donatinnen disciplijn nemen. Ende in die tijt als dat conrent int ghemeen disciplijn ontfanghet sel die priorinnen bisonder disciplijn nemen.

Van silencium dat VIIJ capittel.

34 vo. In der kercken ende in de reventer, in den nounen- ende lekendormiter, die in een side des cloesters gheset is, bi die vier ende in die privaet sellen die susteren tot allen tiden silencium houden. Onder die ghetiden, onder des convents missen, onder die middaechs slaep ende onder eten sellen si silencium houden. Des donredaechs voer Paesschen, opten Goeden Vridach ende opten. Paeschavent sellen si silencium houden nae datter ordinen inhout. Van dat die compleet ut is, totter prym of terci toe des anderen daghes sellen si seer nauw silencium houden 
ende wachten hem oec van corten woerden. Ist datter haestelic brant ontsteken waer in den cloester of binnen haer begrip, so moghen die susteren silencium breken. Desghelijc als een suster met enighe siecte haestelic begrepen wort. Die suster die dat verneemt mach spreken ende haer bedde visitieren. Des heilighen daghes na twalef uren tot dat eerste teiken der vesperen ende als die vesper ut is tot dat eerste teiken ten aventeten moghen si te samen comen bi goetduncken der priorinnen in een bequaeme stede ende spreken van goede ende stichtighen materie of si moghen hem oec gheven totter lerinc of tot heilighe lessen ende totten dienst Goōds te voersien of tot ander gheestelike oefeninghen. Als dat convent in enigher stede mit malcander te spreken vergadert is, soe en sel niemant van daen gaen buten oerlof des outsten ende als si haer boetscap ghedaen heeft sel si weder commen totten convent. Des werckedaghes sellen si strenghelic silencium houden tot dat die vesper

35. ut is, nochtan ist dat den oerbaer of die noot eisschet so moghen si mit luttel woerden, naedat die sake dient, malcander besceit doen, mer twee ende twee te samen en sellen niet spreken boven die tijt van een Miserere mei Deus $\left.{ }^{1}\right)$ Ist dat dieghene die in den arbeit van buten sijn buten dese voerseide tiden ende steden leffen ${ }^{2}$ ) ende satelic ${ }^{3}$ ) spreken, die en sel men niet sculdich houden dat si haer silencium hebben ghebroken. Mer hebben si meer of langher van node te spreken, so sellen si gaen op een openbaer stede die daertoe gheschicket is mit oerlof der priorinnen ende spoeden hem als si eerst moghen ende commen weder totten convent. Want die veel te samen sonder oerlof spreken, die sellen swaerlic ghecorrigiert worden van dien en vermoet men gheen goet ende het is te duchten dat die duvel die derde $\operatorname{van}$ hem is. Nader vesper tot dat eerste teiken tot die compleet moghen die susteren int ghemeen mit malcander spreken, mer woerden die de minne quetsen of daer si malcander mede vertoornen of waerlike woerden van waerliken personen of van waerlike saken moeten verre wesen, mer si sellen spreken van goeden materien, van den heilighen lessen, van die collaci ende dierghelijc ende dat sateliker ende sonder

1) Van "mer twee" enz. tot aan "Ist dat" zijn zeventien woorden doorgehaald.

2) Lelfen verkorting van leffelen $=$ zotte praat, praten, boerten.

3) Satelic $=$ zacht. 
gheruchte. Des daghes eer si ten Heilighen Sacrament gaen, sellen si silencium houden nader collacien ende mit groter naersticheit hem gheren tot devocie. Somwijl bi sonderlinghen oerlof der priorinnen moghen die susteren mit malcander utgaen in den hof ende spreken van gheestelike dinghen tot dat hem

35 vo. van den oversten een teiken ghedaen wort of tot dat teiken tot de ghetiden; nochtan en sel niement alleen of mit een ter side gaen mer si sellen te samen utgaen ende te samen wedercommen. Ende waer yement die anders haer silencium wetende braec, of die callinc in die tijt des arbeits rermenichfoudicht ende vertrecket of dicwijl ledichlic ende onrustelic ommegaet die sel een disciplijn nemen in den capittel, ende ist dat si binnen twee capittelen driewerf of vierwerf daerin sculdich ghevonden wort, so sel si mitter disciplijn, die si ontfanghen heeft oec eens op die aerde eten. Mer die priorinne mach om nootsaken of om oerbaer die kelrewaerster, die kokenwaerten of anderen susteren die diensten berolen sijn een ghemeen oerlof gheven te spreken nadat haer ut die sake der officien duncket oerbaer wesen. Ende die priorinne mach oec selver spreken alst haer noet of goetduncket, ende in haer tegenwoerdichheit moghen al die susteren spreken alst haer behaechlic is. Nochtans sellen die susteren wachten dat si gheen oersaec en soeken te spreken mitter priorinne, of die priorinne mitten susteren in verboden steden sonder merckelike sake, mer billiker gaen tot gheoerlofde steden ende daer haer bootscappen doen. Die procuratrix mach oec spreken mitten ghenen die onder haer dienen alst noot ist, of alst haer verbaer duncket sonder oerlof. Utghenommen die steden ende tiden die gheordineert sijn in te swighen sonderlinghe nae compleet. Als die susteren malcander te ghemoete comen sellen si mit vriendeliker wackerheit ende

36. mit een oetmoedich nighen malcander wikende ende al swighende voerbi gaen. Tot dat eerste teiken des middaechs eten, des a ronts eten of der collacien sellen alle die susteren silencium houden, ende als men dat ander teiken doet mitter scelle gaen si in den reventer.

Tan den arbeit der handen. IX capittel.

Want ledicheit een viant is der zielen ende een voetster der sonden, so en sel niemant van die susteren ledich wesen, mer men sel naerstelic houden, dat des werckedaghes van prijm tot die compleet toe, alle die susteren ende elc bisonder diet vermoghen hem pinen te gheren totten arbeit haarre handen

VI. 
voer den ghemenen oerbaer. Utghenommen die uren ende tiden die si in den dienst Goods wesen sellen of die tijt dat si leren die daertoe geschict sijn. Want niet lichtelic en wort hi verwonnen van die becoringhe die in goede oefeninc becommert is. Want van den $\mathrm{He}(\mathrm{er})$ is gheseit totten mensche, dat hi in den zwete sijns aensichts soude ghespiset worden van sinen brode. Ende die Apostel seit: soe wie dat niet en arbeit en sel niet eten. Ende die propheet: Wanttu den arbeit dijnre handen selste eten, salich bistu ende die sel wel wesen. Daerom dieghene die niet arbeiden en wil, die sel men overmits ontrecken der ghemeenre spisen of dranckes, of in enigher ander manieren also lange penitencien laten doen na goetduncken der priorinnen of des rectoers, thent si haer ghebetert heeft.

36 vo. Die susteren die in de werchusen of anders waer to samen arbeiden, die moghen spreken, leffen ende satelic, van den dinghen die haer werck eysschet. Mer onder den arbeit worden si vermaent dicwijl te lopen tot corten ghebeden als bernende vierpilen. Si sellen hem dan naerstelic gheven tot hare hantwerc ende arbeiden truwelic niet voer hem selven, mer voer den ghemenen oerbaer na utwisinghe der regulen, ende wachten dat si in die tijt des arbeits in gheen werchuse ingaen, mer als si volbrocht hebben daer si om utghinghen sellen si vluchts al swighende weder gaen tot haer werckstede. Hierom sel die priorinne eens ter weke of ter maent van eens yghelics werck rekeninc ontfanghen, opdat men also mercken mach wie vlitich sijn in haer werck of wie versumel sijn. Sie sellen oec op seker uren in die tijt des arbeits lesen die seven psalmen ende vighelien (sic), ende die niet te choer en gaen die ghetiden van den Heilighen Gheest, van den Heiligen Cruus ende dierghelijc. Nochtan mach die priorinne mit sommighen dispensieren die in dat scrijfhuus of in anderen steden enighe sonderlinghen arbeit hebben. Het is mede te weten, dat die susteren der luden clederen van buten niet sniden, noch maken en sellen, ten waer dat bi oerlof des rectoers den gasten wat vermaecten.

$\nabla$ an die spraecstede, dat $X$ capittel.

Als die susteren worden gheeysschet te gaen totten spreec37. husen, so sel men die priorinne eerst te kennen gheren wie si sijn ende wat si willen ende van waer si commen eer ment den susteren segghet. Ende ist dat die priorinne oerlof gheeft 
soe en sel dieghene die gheeysschet wort niet alleen gaen, noch mit dieghene die si wil, mer mit diegheen daer haer die priorinne mede gaen hiet. Daer sellen oec drie of vier susteren ordiniert wesen van den gheestelicsten ende besceydensten, sonder welker een of twee, of sonder die priorinne, niemant van den susteren gaen en sel voer dat spreecreynster der Iuden van buten ende die suster en sel daer niet spreken haer ghesellinne of ghesellinnen en horent. Ende dese sellen die suster daer si mede gheseint worden besculdighen, ist dat si haer in woerden ende ghelaet, in wercken of in enigher manieren mercken sculdich te wesen. Men sal nyemañt sonder merckelike nootsake oerlof gheven te spreken in die spreechusen mit luden van buten of daer in te gaen also langhe als men die ghetiden of des convents misse doet, of alst convent eet of slaept, noch des heilighen daghes, ten waer of si van verren steden quamen ende niet toeven en mochten. Mer nae compleet ende voir die prym en sel men niemant oerlof gheren sonder nootsake die men niet scuwen en mach ${ }^{1}$ ). Gheen suster die gheroepen wort totten spreechusen en sel langher spreken dan een ure lanc buten sonderlinghe oerlof; si en sel daer oec tot ghenen tiden eten of drincken ende dieghene die hier teghen dede, sel men witte-

$37 \mathrm{vo}$. like ende scarpelike corrigieren. Ist dat men drincken of anders wat halen sel, dat en sel haer ghesellinnen niet halen, mer die suster selver die gheroepen is totten spreechusen sel halen die dinghen die noot sijn of si sullen te samen gaen. Ende die totten spreechusen gheroepen is en sel noch utgheren noch innemen, mer die priorinne, is si teghenwoerdich, of dieghene die haer bi geschict is selt doen. Die veynsteren van den spreechusen sellen oec mit yseren tralien wesen ghesloten ende mit doecken ghecleet.

Hoe die sloten ende veynsteren ende sciven ${ }^{2}$ ) sellen wesen dat $X I$ capittel.

Der susteren tymmeringhen sellen oetmoedich wesen ende niet merckelic, overmits curiosicheit of orervloedicheit; ende naerstighe sorghe sel men daertoe doen, dat die werchusen ordiniert worden alst best dienen mach om die religie te houden ende bovenal sel men daertoe sien dattet slot overal ende alom wel hoghe ende sterc si, alsoe dat niemant oersaec en worde

1) Niet vermijden kan.

2) Draaischijf. 
ghegheren in of ut te gaen doer dat slot. Men sel $00 \mathrm{c}$ in een bequaem stede voeghen inder mueren een ront instrument datter mueren oversceydelic anhanghe dat wi een rol of een scijf heeten, door welc men die dinghen die noot sijn alsoe mach gheven ende ontfanghen, dat die ghevers ende nemers nerghens malcander sien en moghen. Daer sel oec wesen een inganc totten slote der susteren door welken men die dinghen die noot sijn totter lijftochte ende dierghelike in draghe mach. Welke ingane sel sterkelic ghevest wesen mit tween versceiden doren, die

38. men sluten sel mit tween sloten ende slotelen, die van malcander scelen in grootheit ende in der formen, dair die priorinne een of hebben sel ende die suppriorinne of die procuratrix die ander; ende die slotel van die butenste doer sel hebben die rectoer des huus, ende als hi ut is sel se sijn ghesel bewaren. Inder kercken mach oec een doer wesen die desghelijc ghevest sel wesen, daer men die susteren die men sluten sel inleiden mach of doer welke die priester, als hi den sieken die sacramenten ministreren sel, ingaen mach. Ende desghelijcs sel oec wesen van die doer des boemgaerts. Opdat alle oersaec des toegancs in den slote ghehelike ofghesloten worde, soe wortet van gracie ghegonnet, dat sel wesen op een bequaem stede ende hoghe een cleyn vejnsterkijn van papiers forme mit yseren ende seer nauwe tralyen, welke men alst noot is ende men den susteren ouders niet weygheren en mach eens of tweewerf siaers opdoen mach, opdat si haer kinder sien moghen (ende mit hem luttel tijts als een seven psalm sonder letanien (sic) lanc mit eerbaerheit ende ripicheit staende ende niet sittende spreken in teghenwoerdicheit des rectoers, der priorinne ende der suppriorinnen of der procuratrixs. Ende ist dat sijt langher verhenghen, so sellen si drie daghen vasten te bier ende te brode. Ende hier en boven sel dat capittel dese voirs. penitencie vermeerre oft hem goet duncket) 1). Van welke veynsterkijn sellen wesen drie slotelen, twee binnen ende een

38 vo. buten onder die bewarinc des rectoers alst is van die slotdoer welke wi voertan starckelike verbieden, dat men se niement open doe dan alleen denghenen die dat die gheestelike rechten henghen. Die hier teghen dede, die sel men van den visitierres of ran den capittel seer swaerlic corrigieren. Alle die veynsteren

1) Hetgeen ik entre-parenthèse gezet heb, is in het hs. met een lijn omtrokken, en in margine zoowel links als rechts staat: văt. Waarschijnlijk : verandert, 
in die spreechuse ende inder kercke daer men biecht hoert, ende of daer enighe ander sijn, sel men maken mit yseren tralien van binnen of van buten ende daer tusschen een bort dwers doerboert of een doorslegen blic ghedect mit een swart of blaeu cleet, also dat overal an beiden siden dat sien ende dat raken der gheenre die daer spreken ghehindert ${ }^{1}$ ) worde. Ende alle die veynsteren of veynsterkijns of oec mede die sciven sellen vän binnen hebben goede houten doren, die men mit slotelen sluten mach ende die ghesloten sellen wesen alst gheen noot en is te spreken of yet in te nemen of ut te gheven. Wi verbieden oec dat men gheen maechdekijns of knechtkijns doer die scive in en laet buten sonderlinghen oerlof des rectoers. Gheboertet dat enighe persoen overmits roekeloesheit onversienlic in den slote quaem, so en sel die niement toespreken of antwoerden of daertoe gaen, mer alle die susteren sellen bi malcander bliven, want si van den rectoer of van de priorinnen utgheleit is. Niemant en hengt men te eten of te drincken in den slote dan alleen den werclude als si ontbiten des ochtens of des afternoens in een bequaem stede ter siden of. Mer totten

39. middendach ende arontmael sellen si altoes utgaen. Ende die wercken des cloesters binnen den slote sel men billiker laten doen van vreemden wercluden dan van diegheen die daer to cost gaen.

$\nabla$ an den inganc in den slote. XII capittel.

Want wi willen dat men grote voersienicheit hebben totten inganc ende totten utganc der susterhusen, soe verbieden wi op die pine der ewigher maledictien, dat nymmermeer enighe professide suster buten den slote en gae dan overmits vrese des brants of des vals hairs cloesters of om rrese der moerdenaers of deser gheliker opvallen die pleghen te geschien in Trese des doots, ten waer dat men bi oerlof des generaels capittels om enighe sake yement $\operatorname{van}$ den susteren sende in een ander huus dat men maken sel of dat ghemaect is. Anders en hengt men niement ut te gaen oec om enighe siecte, tensi dattet generael capittel toelaet en oerloft \%). Die biscop ende die outste prelaet, die vorst, die vorstinne of die vrouwe van den lande, die fundierre of fundierster moghen ingaen mit een eerbaren ende ghematichde ghesinne, ist dat ment te goeder wijs niet onsculdighen en mach. Die visitierres, als si visitieren,

1) Voor deze alinea staat in margine nut" met een andere hand geschreven. Misschien beteekent ook dit: ${ }_{n}$ verandert". 
ende die bi der electien der nyewer priorinnen wesen sellen moghen ingaen, nochtan als si minste moghen; desgelijc mede die rectoer. Ende als si ingaen, so sellen si haar cappen of mantelen mit hem brenghen ende die priorinne mit die suppriorinne of procuratrix sel se ontfanghen ende inleiden ende

$39 \nabla_{0}$. weder utleyden ende en sel nerghent van hem wechgaen. Ende die ander susteren en sellen dan niet ommelopen, mer si sellen wesen in den capittelhuse of in der kerc of in een ander eerbaer stede, utghenomen die van node in sommighe werchuse onledich sijn tot si weder uten slote gaen daer si in sijn ghecommen. Niemant van de susteren en sel spreken mit enighen die van buten incomen rersceiden van den anderen susteren, utghenomen die priorinne ende die mit haer gaen, nochtan dattet een onder hem hoert. Die werclude oec om nootlike wercken moghen ingaen alst den rectoer ende der priorinnen goetduncket mit welken niemant van die susteren spreken en moet, noch daer toe gaen, dan alleen die priorinne, suppriorinne of procuratrix, alsoe nochtan dat si cortelic spreken ende dat si van den anderen ghehoort worden. Waert dat yemant alsoe siec worde dat si niet en mochten comen of gheleit worden tot die ghewoenlike stede des biechtens of des monighens \%), soe sel die priester, in een choercleet met een stool dat Lichaem Christi draghende, gaen tot die sieke suster ende voer hem gaen twee susteren mit waskaersen. Daeran noch twee, van welken die een draghet een lantaern ende een scellekyn dat si ludet, ende die ander ghewiet water ende twee ampullen mit wijn ende mit water ende die priorinne met sommighe van den rijpsten susteren naevolghende, ende dan sel die priester die sieke suster communiceren als in dat manuael ghescreven staet. Mer ist noot, dat si gheolijt worde, so sel die priester aen-

40. doen een choercleet met een stool ende dat heilighe olien mit him draghen. Ende voer hem sel gaen een suster mit ghewiet water, daeran een mit een lantaern mit licht, daeran een mit dat cruus, daeran dat convent mit processi twee ende twee, die iongheste voer, ende also gaen si totten siechuse. Ende als die priester in dat siechuus coemt seit hi Pax huic Domui als int manuael staet. Men sel oec wachten, dat die inganghen niet te reel en vallen, nu orermits sake des moninghens, nu overmits saken des oliens, mer liever sel men beide te samen

1) Communiceeren. 
doen, eerst dat monighen, daerna dat olyen als dat den rectoer goet sel duncken; ende als men yement olijt soe sel dat convent int siechuus bliven tot dat den dienst ghedaen is. Als men oec yement begraven sel, doet die rectoer een choercleet an mit een stool of na der messen hout ') die alve aen, ende als hi der sieken susteren biecht hoort sel hi soe sitten dat desgheens stede die hi haer biecht hoort mit gheen ghardinen betoghen en wort.

Van den Dormiter. XIIJ capittel.

Die dormiter sel men boven maken endehem wort ghegonnet, dat si om crancheit des kunnes bedden van plumen moghen hebben mit linnen slapellaken, mer die sellen grof wesen. Tusschen die bedden sel een onderscot wesen alsoe hoech dat si malcander niet en sien en moghen ende voeran die voerste side mach men maken een onderscot nae der breet des beddes of 40 ro. wat breder, ende voer dat ander sel men hanghen een laken. Buten den dormiter en sel gheen suster enighe camer hebben, mer si sellen allen slapen in den dormiter, behalve dieghene die nootsake der siecten dwinghet van daen te bliven. Ghemeenlic en moet niemant gaen toe des anders bedde of doer soeken dan alleen die priorinne of ten gheschiede bi haren oerlof. Van der compleet totter primen en sellen si nerghent gaen dan om nootsaken der naturen ende totter kercken om den dienst Goods te doen of om hem te warmen naedat die metten ghesonghen is. Want dan sellen si rustelike bi haren bedden bliren ende pinen hem een luttel te ledighen tot hem selven tot Gode, totten heilighen lessen of totten ghebede, opdat si alsoe die voirleden verstroynghe des daghelics arbeits ende van alle ander becommernisse moghen weder verhalen ende alsoe te ruste gaen. Van Paesschen tot die verheffinghe des Heilighen Cruces, opten Palmdach ende opten dach des Gheboerten Ons Heren na die noen of na der gracien nemen si haer middachslaep omtrent een ure lanc. Ende opdat niemant nae datter ghewrecket is langher en vertraghe so mach die costerisse naedat si ghewrecket heeft die bedden weder besien, ende die sculdich vint mach si in den naesten capittel beroepen. Op alle tiden als die susteren slapen, waer datter yemant waer die niet en sliep of die noot hadde op te staen of erghent to gaen, die sel also sedelike ende stillic opstaen, gaen ende wedercomen dat si

1) In margine "hi". 
der ander susteren ruste niet en verstoer. Den Dormiter sel 41. men werckedaghes bi daech ghesloten houden daer dat so dient, utghenomen die tijt als die susteren na ordinanci der priorinnen haer bedden besacken.

$\nabla a n$ den reventer. XIIIJ (capittel).

Alle die susteren sellen te samen comen tot beiden maeltiden als des middaechs ende des avonts. Ist dat enighe suster blivet van der tafel of oec van der benedictie, die sel in den capittel venia bidden ende die sake waerom dat si van der tafel is gebleven daer to kennen gheven. Als men dat clocgen ludet so sellen die susteren vluchts voer den reventer te samen cornen ende daer sellen si sedeliken al swigende sitten thent die outste die reventerscelle : ludet, ende dan sellen si nae ordinancie ingaan, die outste roer ende nighen totten cruus. Wanneer dan die susteren staen choer teghen choer soe beghinnet die ebdomedaria mit mathiger stemmen Benedicite ende die ander suster vervolghen dat vaers met Gloria Patri. Als dan die ebdomedaria nae dat Pater Noster seit Et ne nos, soe sellen si hem alle oprechten ende si seghent ende maket een cruus teghens die outste tafel. Ende als die benedictie bi den eynde is, so gaet die leester int middel ende laegh nighende neemt si die benedictie. Als die benedictio ghedaan is, climmet die leester op die leestoel (sic) en die ander susteren gaen sitten ter tafelen. Die leester sel voer die benedictio voersien wesen van den boeken ende van der stede daer men die lessen beghinnen sal

41 vo. ende dat daer ghenoech si te lesen alle die maeltyt doer. Si en sel mer beghinnen te lesen eer dat gheruchte dergheenre die gaen sitten ofghelaten is, noch die susteren en sellen gheen spise antasten, eer dat men een clausel ghelesen heeft ende sien dat se die priorinne aentast. Die leester mach voer dat middachmael wat eten ende voer die collaci drincken. Si sel alle dinc opelic ende besceidelic lesen dat ment horen mach ende verstaen, ende als si leset sel si haer oeren neyghen totten ghenen diet toehoert te corrigieren, opdat als sijt corrigiert verstaen mach. Die ordinanci van dat lesen beghinnet van den ionghesten opclimmende, ende die in een weke leset in den reventer die sel in die ander weke dienen. Ist dat die leester of dienster ter tafelen ombreket ende niemant anders ghebeden en hevet, so sel des diensters stede vervullen die suster die voer haer gaet ende des leesters stede die na haer rolghet. Ende ist dat enighe suster comet nae der benedictie, 
die sel sitten nae dieghene die gheseten sijn of die ingeghaen sijn to sitten. Mer dieghene die incoemt naedat si alle sijn gheseten, die sel mit oerlof ingaen ende die leste bliven. Die suster die niet eten en mach, dat men haer voerset, die en is niet gheoerloft dat jemant anders to gheren. Als si drincken, sellen si die kanne of die nap mit beiden handen houden, ende der suster die hem yet aendraghet of afnemet, sellen si een weynich nighen ende oec diet aendraecht of afnemet desghelijes. Die tafellaken en sellen si niet toeslaen eer die priorinne het haer toestaet. Die susteren die na den anderen eten, -en

42. sellen niet anders eten dan die ander ghegheten hebben, utghenomen die crancke ende sieken. Als dan die priorinne siet dat alle susteren ophouden van eten, so sel si een teiken doen mitter scellen, ende als Tu autem gheseit is ende Deo gracias gheantwoert, so staen si alle op vander tafel ende die priorinne ludet die scelle een luttel. Ende als die susteren staen in haren steden so sel die suster, die die benedictie ghegheren heeft, dat vaers vander graci beghinnen. Ende als die psalm beghonnen is, so sellen si totten cruus nighende utgaen nae ordinancie, die ionghen voir. Als si int choer comen so nighen si totten altaer ende betalen die gracie alst ghewoenlic is. Buten den reventer ende buten den siechuse en sel gheen suster sonder noot eten. Dieghene die buten den reventer eten, die nighen een weinich tot Pater Noster ende tot Gloria Patri. Ende totter gracien moghen si segghen die psalm Laudate Dominum omnes gentes.

$\nabla$ an dat vasten $X \nabla$ (capittel).

Van die verheffinghe des Heilighen Cruys (totten advent ende van dertiendach totten zonnendach in Quinquagesima sellen die susteren des) ${ }^{1}$ ) woensdaghes ende des vridaghes eens eten, utghenomen hoochtiden van neghen lessen die op die woensdaghen comen. In den advent vasten si alle daghen sonder vleesch, nochtan mach di priorinne mit sommighe dispensieren bi consent des rectoers; mer binnen den advent mach si bi haer selven mit sommighen dispensieren om merckeliken arbeit of om redelike sake, mer niet mit dat heel convent sonder consent

42 vo. des rectoers. Des daghes als men een nyewen rectoer of een nyewe priorinne ontfanghet, of als men enighe suster cledet of

1) Door de schrijfster of den schrijver is een regel opengelaten, welke later door dezelfde hand is ingevuld. Daar de opengelaten ruimte te min was, zoo heeft men de beide marges beschreven. Die regels heb ik tusschen haakjes gezet. 
professijt sellen si tweewerf eten, ten waer oft een botvast waer. Des woensdaghes en sellen si gheen vleysch eten, utghenomen die seer merckelike siec sijn. Op Onser Vrouwen avonden ende in die vigilien van Kersmisse, Ons Heren Hemelvaert ende Pinxteren ende Alre Heilighen ende van die sonnendach in Quinquagesima tot Paeschdach toe, sellen si vasten sonder zuvel. Mer in anderen botvasten ende des vridaghes sellen si hem gheliken der zeden des landes, utghenomen dat si niet lichtelic eyer en eten, ten waer datter merckelike gebrec van vissche waer; mer dien ziecken ende crancken gunt men bi oerlof der priorinnen eyer te gheren. Den gasten moghen si gheven also als si selven eten. Opten Goeden Vridach sellen si hem ghenoeghen laten mit broot ende bier mit tween pottagien ende mit een harinc of een bockinc, die sieken utghenomen. Des vridaghes in die paeschweke eten si tweewerf ende opten Kersdach of wat dach dat hi coemt sellen wi (sic) (si) tweewerf vleysch eten. Op sinte Marcus des Evangelistendach, des manedaechs in die bededaghen ${ }^{2}$, op des waerdes Sacramentsavont ende op onse vader Augustijnsavont ${ }^{3}$ ) sellen wi (sic) (si) sonder vleysch vasten als in die vasten der oerden. Mar waert dat sinte Marcusdach quame in die weke van Paesschen so en rasten si

43. niet, noch en doen gheen abstinenci om die letanien. Disciplinen of abstinencien of wakinghe of enighe lichaemlike oefeninghen, die van onsen ghemeen insettinghe niet en sijn, en sijn niemant gheoerloft to doen, tensi dat die rectoer dat weet ende ghonnet.

Van der collacie ende dranck. $X V I$ capittel.

Op die daghen als men niet dan eens en etet, so sel die reventerwaert luden totter collacie te $\mathbf{v}$ uren na der resper ende als die susteren vergadert sijn, sel die priorinne die reventerscelle luden. Daerna als die susteren inghegaen sijn, so eysschet die leester int middel die benedictie. Hier volghet die benedictie noctem quietam vitamque beatam tribuat nobis omnipotens et misericordis Dominus. Amen. Ende alsdan een clausel ghelesen is ende van der priorinne een teyken ghedaen is, so seit die loester sittende Benedicite. En die ebdomedaria, desghelijc

1) In het reglement van Betlehem worden nog genoemd S. Ian Baptist en S. Petrus en Paulus.

2) De Kruisdragen.

3) Noch in de statuten van Albergen, noch in die van Betlehem wordt gesproken van nonse Vader Augustijsavont". 
sittende, benedijt den dranc mit een teiken des cruces segghende Largitor omnium bonorum.

Als dan derdewerf dranc ghescencket is, so sel die leester totten teiken der priorinne segghen Tu autem Domine. Ende als Deo gratias gheseit is, seit die ouste Adiutorium ende also sellen si swighende wedergaen op haer werc. Buten die maeltiden ende collacien en sel niemant drincken, tensi bi oerlof of als men dranc doert convent andient buten den reventer.

Van der biecht ende communiceren. XVII capittel.

Tot viertien daghen sellen die susteren eens biechten ende communicieren, ten waer dat enighe suster wittelike ghehindert

$43 \mathrm{vo}^{\circ}$. dat vertoghe bi witen ende consent des rectoers. Nochtan om meerre dubbelde honchtiden of solempne mach men die communicaci een deel daghen voercomen of vertoeven. Des donredaghes voer Paesschen ende opten Paeschdach sellen si allen communicieren. Dieghene die communicieren sellen, die gaen na Agnus Dei ut haer stoelen ende legghen neder op die stede daert ghewoenlic is. Ende als die priester comet, sellen si malcander nae ordinancie volghen ende den priester gheen merrinc ${ }^{1)}$ of vertoeninc maken. Ende als si dat Lichaem Ons Heren ontfanghen hebben, sellen si wiken totter ander side, ende als si daer een luttel tijds gheknielt hebben, nemen si onder hem abluci ende gaen weder tot haren stoelen. Het is mede te weten, dat die susteren altoes des daechs voer dat si communiceren sonder vleysch vasten sellen ende dan en sellen si oec dat huusghesin buten gheen vleysch gheren. Als si opten sonnendach communicieren omdat si den rridach ghevast hebben, sel men hem des saterdaghes int avontmael ten reventer gheven pottagi, butter en caes, een ey of een appel. Ist dat enighe suster tusschen tiden noot heeft te biechten of den rectoer te spreken, die sel hem dat bi der priorinnen of bi een die tot sijnre sciven dient laten weten ende die rectoer alset hem dient sel die suster ombieden ende horen in dat biechthuus of tot een ander stede bi die scive ende als si onboden is en sel si niet merren, mer terstont comen ende die schijfwaert sel dat voer of nae der priorinnen segghen, opdat si bekennen oec des susters utwesen of absencie.

44. Van scheren dat XVIII capittel.

Achtwerve binnen siaers moghen die susteren haer hoofden

1) Merringhe = draling, langzame voortgang. 
wasschen ende scheren. Als bi Kersmisse, omtrent Lichtmisse bi Paesschen, voer Pinxteren, omtrent Onser Vrouwe Visitatio, voer Onser Vrouwe Assumptio, voor sinte Michiel ende voer sinte Mraertijn, ten waer dat die priorinne om siecte of om ander sonderlinghe saken yement oerlof gave buten dese tide te scheren. Onder dat wasschen ende scheren sellen si silencium houden, ten waer of si luttel woerden binnen monts spraken die totten wercke noot sijn.

Van laten XIX capittel.

Vierwerve des iaers sel men ghemeenlic laten, buten welken tiden men niemant lichtelic ende sonder openbaer ende wittelike sake oerlof gheven en sel. Die eerste sel wesen bi Onser Vrouwe Lichtmisse : voer of nae, die anderde in Mege, die derde na sinte Berthelmeeus of in Septembri, die vierde sel wesen in Novembri. Als die susteren ${ }^{\text {l) }}$ laten, sel die rectoer den later helpen totten slote toe ende die priorinne sel bereit staen mit die suppriorinne of mit die procuratrix om die later te ontfanghen ende te leiden tot dier stede daer men laten sel ende die rectoer gaet weder tot syn woninghe ende als dat laten ghedaen is, doet hi dat slotdoer op ende laet die later weder ut. Die priorinne sel $\mathrm{bi}^{2}$ ) die susteren bliven die wile dat si laten ende vermanen dat si hem scameliken ende ripelic hebben ende dieghene die niet en laten en sellen niet comen tot dier

44 vo. stede daer men latet. Op die ghemeen lateltiden sellen die niet ghelaten en hebben dieselve goedertierenheit ghenieten mitten ghenen die ghelaten sijn, ende dieghene die laten sellen, die sellen to samen laten. Op die tijt dat men latet, moghen si spreken binnen mondes ende mit luttel woerden sonder gheruchte van den dinghen die in die tijt noot sijn oec mitter later; nochtan dattet enighe van den outsten susteren hore. Ende drie daghe aftereen eten si tweewerf wat beter spises nemende, ten waer of daer een botrast tusschen quamen. Men sel nochtan voersien of men ghemalic mach dat binnen tween daghen alsulke vasten niet en comet. Die susteren en sijn oec niet verbonden binnen desen daghen totter strenghicheit des swighens, behalve van compleet tot na der primen ende onder die ghetide ende in der tijt der lessen ende in der steden die ghesacket sijn dat men daer swighen sel. Des eersten daghes na den eten of in

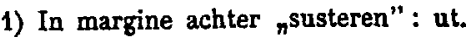

2) Id. achter "bi" onderstreept. 
die somer alser gheslapen is als die priorinne een teiken hevet laten doen, sellen si al te samen comen int pant. Ende daerna als een cleyn lessen ghelesen is gaen si te samen ut in den boemgaert ende in den hof, tot dat men dat eerste teiken ter versperen doet, ten waer dat den ousten goetdochte, dat men eer weder soude ingaen. Des anderen ende des derden daghes als si te samen eten, sellen si wat goets spreken. Die susteren die buten die ghewoenlike lateltiden mit oerlof laten, die sellen hebben des eersten daghes die goedertierenheit als hem pater

45. ende mater sacken, mar die twee naerolghende daghen wordt hem alleen ghegheren dat avontmaal, ten waer datter botrast waer.

Van die conversinnen $X X$ (capittel).

Die conversinnen sel men ontfanghen als die nonnen. Want ghelyc den nonnen, worden hem harde ende scarpe dinghen voergheset, ende dieselve dinghen worden hem gevraghet die men die nonnen vraghet. Hier en boven sel men hem die oefeninghen der utwendigher arbeiden te voren segghen. Want haer staet sonderlinghe ingheset is totten diensten des huses. Si sellen haer proeveliaer hebben als die nonnen ende men sel hem een meestersse setten die dat oghe op hem heeft. Haer dinghen sellen si der priorinnen of een ander diet die priorinne beveelt te bewaren gheren. Als men se cleden sel, doet men den dienst als van den nonnen, mer si en singhen dat vaers niet van Regnum mundi. Haer habijt sel wesen een witten roc met een swart scapulier, mer der novicenscapulier sel corter wesen totten knyen toe ende die professyt sijn beneden ten halven kuut toe. Als dat iaer haerre proevinc ut is, worden si in den capittel totter professien ontfanghen ende si scriven haer professi. Ende ist dat si niet lesen of verstaen en konnen, so sel haer meestersse leren verstaen, opdat si weten moghen wat haer professi inhoudet. $\mathrm{Na}$ derselver manier doet men haer professi als der ander nonnen, utghenommen dat si dat vaers Suscipe me Domine niet en lesen, mer vluchts als si ghecledet sijn ende Regnum mundi mitter collect gheyendet is, lesen si haer professi

45 vo. in dier maniere als voer van den nonnen ghescreven is. Die ander dinghen sel men doen als dat manuael inhoudet. Haer clederen ende bedden sellen wesen als der nonnen, utghenomen dat si die wijl niet en hebben ende voer dat subtijl draghen si een scapulier. Diegheen die ontfanghen sijn totten staet der conversinnen ende gheprofessyt, die en sel men niet verheffen totten staet der nonnen sonder oerlof des generaels capittel, welke 
oerlof men nochtan niet lichtelic gheven en sel. Voer die conversinnen die ghesturven sijn, doet men datselve dat men voer den nonnen doet, utghenomen dat men die souter int choer niet en leset.

Hoe si hem hebben sellen in den dienste Goods ende van haer ghetiden XXI (capittel).

Die 1) conversinnen sellen des heilighen daghes in den kercken to metten ende totten anderen ghetiden comen op dieselve tijt ende mitter selver haeste als die andere in die stede die hem daertoe ghesacket is ende daer haer ghetide lesen. Ende ist datter enighe ghemercket worden dat si, dat si den capittel haer scult spreken ende men sel se corrigieren. In die meerre dubbelde feesten ende daerboven sellen si wesen in die eerste vesper ende compleet, ten waer of si om sonderlinghe saken mit oerlof behoefden ut te bliven. Des werckedaghes als men metten leset, sellen si in der kercken wesen tot die Laudes toe, ghelikerwijs als die nonnen die niet te choer en gaen ende daer en binnen lesen si haer ghetiden ende also gaen si op haer werc. Si sellen missen horen, is dat is ghemaclic moghen.

46. Ende ist datter enighe meer of dicker, overmits enighen dienst of werc, uter kerc bliven, dat sel gheschien mit oerlof der priorinnen of des procuratrixs. Dese verlichtinghe sel men oec houden in anderen observancien der conversinnen als sommighe tot sulke wercken of diensten gheset sijn in welken si ghemeen insettinghe niet wel houden en moghen, want die ghehoersamheit wort voer alle haer observancien gheset. Wanneer die conversinnen tot haren ghetiden in of utgaen so nighen si ten oesten ende staen totten oesten, thent dat luden ghelaten is ende dan lesen si haer Pater Noster knyelende of nighende. Tot Deus in adiutorium teikenen si hem mitten convent. Tot Gloria Patri nighen si. Nae Alleluia of Laus tibi Domine lesen si haer ghetiden. Die haer vrouweghetide in duutsche niet lesen en konnen, die sellen voer die metten lesen driewerf ses Pater Noster ende ses Ave Maria ende na elke ses Pater noster sellen si lesen Gloria Patri, sicut erat. Ten laetsten naedat alle die Pr. nr. ghelesen sijn, sellen si an Gloria Patri ende sicut erat lesen Kiri eleyson, Christe eleyson, Kiri eleyson, Pater noster, Benedicamus Domino, Deo Gratias. Mer in hoochtiden van neghen

1) In margine staat "văt". Waarschijnlijk moet zulks beteekenen : verandert. 
lessen ende daerboven sellen si vijfwerf ses Pater Noster lesen mit Gloria Patri tot elke ses, ende mit eynde Kiri eleyson, als voer ghescreven is. Voer elken van den anderen ghetiden sellen si lesen vijf Pater Noster ende vijf Are Maria, Kiri eleyson, Christi eleyson, Kiri eleyson, Pater Noster, Benedicamus Domino. Mer voer die resper tien Pr. Nr. mit Kiri eleyson. Wanneer haer metten ut is, sellen si, naedat si van haren meesterssen 46 vo. gheleert sijn, devotelic den Heer bidden voer menigherhande personen ende staten der heiligher kercken, als voer den paeus, voer den biscop, voer den Keyser of coninc, voer den prince van onsen lande, voer alle die heilighe Kercke ende prelaten ende princen of vorsten, voer vrede ende vruchten der aerden, voer den rectoer, voer die priorinnen ende haer convent ende voer den ghemenen staet des huses ende onser ander husen. Voer den becoerden ende doden ende voer ander toecomende saken na der tijt ende dierghelyc ende lesen Pr. Nr. voer sommighe meer of min of ander ghebeden naedat si die tijt hebben. Wanneer men dat evangelium totter metten of ter missen, Te Deum, Benedictus, Magnificat ende Nunc dimittis leset of singhet ende oec als men Sanctus ende Agnus singhet staen si alle op. Tot Confiteor ende totten collecten, als sijt mercken dat ment leest, nyghen si als die andere. Mer ist, dat si in der kercken niet en sijn, soe sellen si nochtans des morghens vroech haer prym betalen ende onder die misse, ist dat si se horen of onder misse tijt, sellen si tercie, sext ende noen lesen, mer opten daghen dat men tweewerf etet, sellen si noen billiker na den eten lesen, ende vesper to respertijt of te minste voer dat arontmael ende compleet mit dat convent of naedat si werc ghelaten hebben. Van den beghinnen van der vasten tot Paesschen toe, utghenomen die sonnendagen, sellen si alle daghen die seren. penitenci psalmen lesen of seven Pr. Nr. Si sellen hem truwelic 47. gheven tot haren hantwerc; noch si en sellen gheen dinc dat hem bevolen wort traechlic of versumelic doen of die procuratrix sel se berispen, ende ist dat si hem niet en beteren, so sellen si van den rectoer of van der priorinnen spaerlic ghecorrigiert worden. Haer silencium sellen si pinen te houden in tiden ende in steden als die ander die in den arbeit sijn. Ende als men mit hem ende mit die nonnen eens tot viertien daghen capittel hout, so ontfanghen si haer capittel nae die donatinnen ende so gaen si ut. Ende gheliken die nonnen ontfanghen si disciplyn. 
Dan die Donatinnen $X X^{1}$ ) capittel.

Die donatinnen, die na den gheesteliken rechten gheoffert worden gheheten, die sellen in die sacristie voer een notarius mit tughen, simpelic ghehoersamheit loven ende ghetrouwe te wesen den huse mit overghevinc alle haere goederen sonder wedereysschinghe, welken dan die rectoer van des conventsweghen wederomme loven sal sonder twivel besorghine van alle dinghen tijtlic ende gheestelic ende dat se dat convent om ghene siecten of enighe ander saken tot enigher tijt van hem setten sel, ten waer dat God verbieden moet, dat si also ghevonden waren dat men se niet corrigieren, noch tot enighe beteringhe brenghen en mochte ende die visitierres rieden, dat men se om haerre utmutende hardicheit utsetten soude ende dan en sel men hem van dat si inghebrocht hebben niet weder gheren. Waer dat enighe uten cloester liepen, die is dat convent sculdich te soecken ende weder te halen of si moghen, 47 vo. ende ist dat die reden dat eysschet in die kerker te setten. Haer habyt sel wesen van graewen of van swarten laken mit een swart caproen ende dat seer simpelic ende niet curioselic ghemaket ${ }^{2}$ ). Sie sellen hem gheven totten arbeit als die conversinnen ende datselve dat men den nonnen doe na haerre doot, dat sel men hem mede na doen (hierachter in margine met een andere hand "utge" (nomen). Ende int capittel der nonnen als si haer scult ghesproken hebben of haer gebreken van den anderen ghehoort hebben sellen si voer die conversinnen utgaen. Haer ghetiden sellen si mitten conversinnen ende als die conversinnen houden, ende in den reventer sellen sie nae die conversinnen sitten. Si en sellen gheen werc, hetsi in den slote of daer buten, om enighe snoetheit of pijnlicheit rersmaden, mer nu binnen, nu buten, alst den rectoer ende der priorinnen goetduncken, sel den ghemeente truwelic dienen. Mer die den convente buten dienen en sel men niet henghen dat si bi die sieken in waerliken husen vernachten ende die rectoer sel mit hem alle maents buten die slote capittel houden in teghenwoerdicheit der priorinnen, suppriorinnen ende des procuratrixs. Si sellen die procuratrix ghelijc die conversinnen in allen arbeidelike saken ghehoersam wesen als den rectoer of der priorinnen, bekennende ende hebbende God tot een ewich ende waer-

1) Er moet staan XXII; de twee is echter uitgekrabt.

2) Hetgeen nu volgt is doorgehaald. 
dich loon haers arbeits. Die rectoer ende die priorinne sellen hem setten een meesterse die hem die letteren ende heilighe oefeninghen leert, opdat si alsoe overmits goede oefeninghen ende heilighen sweten ende arbeiden, die si voer den susteren om Godswillen doen, waerdich moghen wesen te comen tot.... 1).

48. Die donatinnen sellen der heilighen daechs inder kercke te metten ende totten anderen ghetiden comen op dieselfde tijt ende mitter selfder haest als die ander in die stede die hem daertoe ghescickt is ende daer haer ghetiden lesen. Ende ist datter enich ghemerckt worden, dat si te laet ter kercken comen, die sellen als die ander susteren in den capittel haer scult spreken ende men sel se corrigieren. In die meerre dubbelde feesten ende daerboven sellen si wesen in die eerste vesper ende compleet, ten waer of si om sonderlinghe saken mit oerlof behoefden ut te bliven ${ }^{2}$ ). Des werckedaechs als men metten leest sellen si in der kercke wesen tot die Laudes toe, ghelijckerwijs als die nonnen die niet te choer en gaen ende daerenboven lesen si haer ghetiden ende alsoe gaen si op haer werck ${ }^{3}$ ). Si sellen mis horen, ist dat si ghemackelic moghen. Ende ist datter enighe meer of dicker overmits enighen dienst of werc uter kercken bliven, dat sel geschien mit oerlof der priorinnen of der procuratrix. Dese verlichtinghen sel men oec

$48 \mathrm{vo}$. houden in anderen observancien der donatinnen als sommighen tot sulke wercken of diensten gheset syn in welcken si die ghemeen insettinghe niet wel bouden en moghen, want die ghehoersamheit wort voer al haer observancien gheset. Wanneer die donatinnen tot haren ghetiden in of utgaen soe neyghen si ten oesten ende staen totten oesten, thent dat luden ghelaten is ende dan lesen si Pater Noster negghende of knielende tot Deus in adiutorium teikenen si hem mitten convent. Tot Gloria Patri nejghen si, nae Alleluia of Laus Tibi Domine lesen si haer ghetiden. Wanneer haer metten ut is, sellen si, naedat si van haerre meesterse gheleert sijn, devotelike bidden voer menighander personen ende staten der heiligher kercken: als voer den paeus, voer den biscop, voer den keyser of coninc, voer den prince van onsen lande, voer al die heilighe kerc ende prelaten ende princen of vorsten, voer vrede ende vruchten der aerden.

1) Hier eindigt de doorhaling. Hetgeen nu volgt is niet op perkament, maar op papier, met een andere hand geschreven en naderhand in het HS. met garen ingenaaid.

2) Doorgehaald tot 3).

VI. 
Foer die rectoer, voer die priorinnen ende haer convent ende voer den ghemenen staet des huus ende onser ander husen.

49. Foer den becoerden ende dooden ende voer ander toecomende saken na der tijt ende dierghelyc ende lesen Pater Noster voer sommighen meer of min of ander ghebeden naedat si die tijt hebben. Wanneer men dan $\left.{ }^{1}\right)$ dat evangelium totter metten of ter misse, Te Deum, Benedictus, Magnificat, Nunc dimittis leest of singht ende oec als men Sanctus ende Agnus Dei leest of singht staen si al op. Tot Confiteor ende totten collecten als syt mercken dat men leest stae $^{2}$ ) neyghen si als die ander. Mer ist dat si in der kercke niet en sijn, so sellēn si nochtan des morghens vroech haer prym betalen ende onder die misse, ist dat si se horen of onder mistijt, sellen si tercie, sext ende noen lesen. Mer op die datthem als men twiewerf eet sellen si noen billicker nae den eeten lesen ende vesper te vespertijt of ten minsten voer dat avontmael ende compleet mit dat convent, of nadat si werck ghelaten hebben van den beghin van der vasten tot Paeschen toe, utghenomen die sonnendaghen, sellen si alle daech die seren penitencie psalmen se ${ }^{3}$ ) lesen of seven Pater Noster. Si sellen hem trouwelic gheven tot haren hantwerck ende totten arbeit. Ende si en sellen ghien werc, 49 vo. hetsi in den slote of daer buten, om enighe snoetheit of pijnlicheit versmaden, mer nu binnen, nu buten, als den rectoer en die priorinnen goetduncken, sel die ghemeent trouwelic dienen. Si en sellen ghien dinc dat hem bevolen wort traechlic of versumelic doen of die procuratrix sel se berespen. Ende ist dat si hem niet en beteren soe sellen si van den rectoer of van die priorinnen swaerlic ghecorrigiert worden. Haer silencium sellen si pinen te houden in tiden ende stede als die ander die in den arbeit sijn. Ende int capittel der nonnen, als si haer scult ghesproken hebben of haer ghebreken van den anderen ghehoert, sellen si utgaen. Ende datselve dat men den nonnen doet na haerre doet, dat sel men hem mede nadoen. Mer die souter on hout men niet int choer. Ende ghelijc die nonnen ontfanghen si disciplyn. Si sellen die procuratrix in allen arbeidelicken saken ghehoersaem wesen als die rectoer of der priorinnen bekennende ende hebbende God tot een ewich ende

1) Doorgehaald $n$ dan".

2) Id. nstae".

3) Id. nse". 
waerdich loen haers arbeits. Die rectoer ende priorinnen sellen hem setten een meesterse, die hem die letteren ende heilighe

50. oefeninghen ende heilighe $\left.{ }^{1}\right)$ heilighen sweten ende arbeiden, die si voer die susteren om Goodswillen doen waerdich moghen wesen te comen totten ewigher vroechden. Amen ${ }^{2}$ ).

Van bichte scult XXII (capittel) ${ }^{3}$ ).

Lichte scult is dat yemant als een teiken ghedaen is alle dinghen afterghelaten thants niet en comet mit riper haeste ende te tide totter stede daerom dattet teiken ghedaen wort. Oec of enighe suster niet aendachtelike en volbrochte enighe officien van lesen of van singhen dat haer toegheteikent is, of dat yemant een respons of antiffen of anders wat beghinnen soude ende dat choer turbeerde. Of dat yemant qualicke lasen of songhe ende confuus dede ende si vluchts voer hem allen niet en veroetmoedichde op die aerde te tasten. Of datter enich boec daer men in lesen soude in die collacien of in den capittelhuse of in der kerken by yemants versumenisse ontbrake. Ghelike scult ist of yemant van den susteren totter tafel of totter collacien of totter capittel of totter ghetiden in der kercken of totter ghemenen werchuse haestelic niet en quame of totter lessen der tafelen gheordineert te late quaem die benedictie te eysschen. Of dat yemant in den dormiter of anders waer in den convent enighe gherufte makede of die suster in haren ghebeden of in haren lesen of studeren of in haren arbeide erghent in verstoerde. Item lichte scult is dat jemant van die susteren een waskaers of enich dinc van den huusrade verloren brake of jet van haren clederen brake of verarghede of verloer. Of dat yement in den dienst Goods of in der collacien of in 50 vo. den werchuse ontslapende 4 ) worde ${ }^{3}$ ), of die wildelic mitten oghen doer dat cloester of doer dat huus tot ydelheden dicwijl omme saech. Of dat yement hem tot ydelen sermoenen leghede of lichtraerdeliken lachte of anderen susteren tot lachen brochte, of dat si in enighen ghelate of zeden of in gaen of in staen of in habyt of in woerden berispelic scheen te wesen. Voer dese sculden sel men setten een psalm of meer nae grootheit

1) Doorgehaald.

2) Hier eindigen de regels welke door een andere hand op papier zijn geschreven. De vorige hand vervolgt het schrift op perkament.

3) In margine staat "Non legatur ad mensam".

4) Droomend, druilend, slaperig.

5) Doorgehaald. Een andere hand schreef er boven nwort". 
der ghebreken als denghenen die capittel hout goetduncken sel. Van middelbaer scult XXIIlJ capittel.

Middelbaer scult is of enighe suster tot Gloria Patri van den eersten psalm niet te choer en waer, ende int midden des choers totten Sacrament ghekeert die aerde te cussen niet en voldede, of opten Kersavont in den beghin des capittels daer niet en waer om, als men daer leset dat beghin onser verlossinghe, dancbaer te wesen Onsen Verlosser mit harten ende mit lichame. Ghelike scult is of yemant van den susteren in den choer niet aendachtich en waer onder den dienst Goods, mer mit wilden oghen ende mit ongheesteliker wise daer toende lichtraerdicheit haers harten. Of dat yement op ghesette tijt sijn lesse niet en voersaghe of die hem vermate anders te lesen of te singhen dan dat gheordiniert is. Of oec yemant in den choer lachte of die andere lachen dede, of in den convent enighe lichtvaerdicheit dede of maecte. Item middelscult is of yemant van den capittel

51. of van der collaci of van der ghemeenre maeltiden of van den werchuse of $\operatorname{van}$ enighe ghetide sonder redelike sake bleve, of dat yemant enighe spisen of dranc name sonder enighe benedictie of segheninc. Ghelike scult is of yemant beroepen ${ }^{1}$ ) waer ende si haerselven wrekende desselven daghes weder beriep daer si of beroepen is. Of dat yemant alst int spreken pleecht te vallen wat mit sinen eede of zweren starcte of missaecte, of enighe oneerlike reden sprake. Of dat yemant in ghewoente hadde te nomen een suster bi haer naem ende afterliet dat woert suster. Voer aldusdanighe sculden sel men setten psalmen, disciplinen in den hals ende renie nae besceydenheit der ouste, aenghesien die grootheit van den sculden.

Van sware scult $X X \nabla$ capittel.

Swaer scult is of yemant kijf of twist makede in dat beroepen of tot dieghene daer si of beroepen is of tot yemant anders vermaledidende of ongheordinierde of ongheestelike woerde sprake. Ghelike scult is of enighe onder den susteren twidrachticheit sayende of een afterspraecster of ruunster ${ }^{2}$ ) bevonden worde of dat enighe suster quade dinghen van den susteren boeflike utsprake; of dat jement sijnsselfs scult of eens anders wredelike bescermede; of dat yemant wetende loghen sprake; of dat yemant in ghewoenten brochte silencium niet te houden.

1) Beschuldigen.

2) Fluisteraarster. 
Item swaer scult is of yemant die ghesette vasten brake of in den spraechuse bi den luden van buten ate of droncke; of dat yemant teghen enighe suster smadelike woerde of lelike reden sprake. Voer als dusdanighe sculden ende deser ghelgc sel men

51 vo. setten penitencie: een middachmael op die aerde te eten ende een disciplyn to nemen in den capittel "voer alle die susteren of meer, ende psalmen ende venien naedattet recht ende behoerlic schijnt te wesen nae den misdaden meerre of minre. Item dat enighe suster mit een ander kijf hadde of oneersamlike twiste, of dat yemant den anderen lasterliken sprake. of den anderen enighe scult verweet daer si of voldaen heeft. Voer dusdanighe sculden sel die voerghescreven penitencie doen ende daerenboven sellen si malcander in die camer nae die gracie voer alle die susteren haer voeten wasschen ende cussen. Item of dat sake waer dat enighe suster enighe dinghen naem sonder oerlof die enighe suster toe ghescicket sijn, nochtan niet mit wille te houden; of dat yemant blere van den ghemenen slape sonder sake of oerlof, die sel een middachmael op die aerde eten ende oec in den capittel een disciplyn nemen.

Van die swaerre scult $X X V I$ capittel.

Swaerre scult is dat yemant mit hardicheit ende mit openbaer wederspannicheit sinen oversten onghehoersam waer, of die so koen waer, dat si mit haren oversten twiste in wreetheit. Of dat yemant den anderen boselike smete. Of dat yemant enighe dinghen die enen anderen ghegonnet waren of van den ghemenen goede name mit wille te houden of als sijn eyghen hielde. Ghelike scult is of yemant ghiften of ander dinghen sonder oerlof wechgave of ontfeng; of als sijt ontfanghen hadde verhude $\left.{ }^{1}\right)$. Of dat yemant brieve of enighe dinghen

52. in scrifte seynde of ontfeng sonder oerlof, of lase of liete lesen. Of dat yemant enich oneersamich dinc des huus of der susteren of enich dinc dat heymelic is enich mensch buten huus te kennen gave. Of, dat God verbieden moet, enighe openbaer dootsonde bedreef. Voer aldusdanighe sculden dieghene die daer sculdich is sel venien bidden in den capittel ende disciplinen ontfanghen ende mit dat penitencicleet op die aerde eten een dach of meer, nae goetduncken der ousten. In deserselver manieren sel penitenci doen of yemant, dat God verbieden moet, gherallen waer in die sonde des vleyschs, welke wi oerdelen, dat men se swaer-

1) Verbuden $=$ verbergen. 
liker corrigieren sel dan enighe ander sonden ende meer in onwaerde hebben dan alle anderen sonden. Dese sel venia bidden ende die grootheit haerre scult sel si screyelic in den capittel beliden ende sel haer bloot maken totten gordel toe ende sel slaghe nemen voer den voeten van alle die susteren: ten eersten van de priorinnen ende daernae van beiden siden der susteren die daer sitten ende si sel die laeste bliven ende comen. Daerna sel men se ofsceiden van dat gheselscap der susteren ende sluten $s \theta$ in een ofgesceiden stede also langhe als dat den capittel of den oversten prior of den visitierres bi sijn consent goetduncken sel. Ende als si bi consent van hem, als voer gheseit is, utghelaten wort en sel si $0 \theta \mathrm{C}$ in den reventer totter ghemeenre tafelen mitten anderen niet eten oen wijl tijts naedat dat den rectoer ende der priorinnen goetduncken sal, mer int middel des reventers van der aerde ende men sel haer besorghen grover broot ende dunne bier, tensi dat sake dat die ouste haer anders wat

52 vo. ut ontfermhtigheit ghevet; noch dat relyf ${ }^{1}$ ) van haren eten en sel men niet doen mitten anderen. Totten ghetiden van den choer en totter gracie na den eten sel si legghen voer die kercdoer, dat die susteren, als si in ende utgaen, over haer treden moghen. Gheen suster en sel soe koen wesen dat si bi haer si of haer wat ombiede. Dese suster also langhe als si in dese penitenci is en sel si niet communicieren, noch men sel se ghenen dienst setten in de kercken, noch men sel haer gheen offici of dienst berelen. Mer die priorinne, opdat dese suster niet en valle in mishope, sel tot haer senden sommighe van den ousten, die se vermanen tot penitenci, stercken tot verduldicheit, voeden overmits mededoghen, troesten tot beteringhe ende helpen mit haren ghebeden. Ende dat ghemeen convent sel haer to hulpe comen ist dat in haer scijnt behoerlike oetmoedicheit. Ende die ouste en sel niet versmaden mit haer ontfermherticheit te doen. Die al sulc is mach men ofnemen haer wile also langhe als si in deser penitencien is. Mer ist dat dese sonde heimelic is, so sel men dat ondersoeken ende dan sel si waerdighe penitencien daervoer doen. Waer dat sake dat enighe susteren mit tsamenspanninc of besweringhen of mit boser eendracht teghen den rectoer of der prioninnen openbaerlic hem oprichten, die sellen in gheliker wise, als voer gheseit is van swaere scult, penitenci doen ende si sellen die laetste stede

1) Overblijfsel. 
houde, ende in den capittel en sellen si gheen stemme hebben, noch gheenrerhande offici of dienst, en sel men hem bevelen.

53. Mer waert dat enighe susteren niet boseliken, mer inder waerheit yet hadden teghen der priorinnen dat men niet verdraghen en soude, so souden si haer doer die suppriorinne mit alre oet. moedicheit vermanen, ende waert dan als si dicwijl vermaent waer, dat si haer versuumde of versmade te beteren, dat soud men den rectoer of den visitierres te kennen gheven of den ousten prior.

Van die alreswaerste scult XXV1 (capittel).

Die alreswaerste scult is als yement niet ghecorrigiert en wil wesen, die hem niet en ontsiet dat quaet te bedriven ende versmaet penitencien daervoer to doen. Daernm ist datter yemant alsulc ghevonden wort, dien sel men uttrecken dat habyt der susteren ende sluten se in ofghesceiden stede ende si sel ghebruken alsulke spisen als voer ghesproken is van die sonde des rleyschs. Tot correctien deser susteren sel men hebben sommighe steden die daertoo dienen, daer men niet alleen die men niet corrigieren en mach, mer oec die proeflic scadelic sijn of daer men qaet op rermoedet van enighe scade te doen in personen of in goederen of van wech te lopen insluten mach. Men mach oec om ghebreke die minre sijn dan dese sommighe setten in die dusdanighe steden ghesceiden van den convent om daer een wijl tijts te wesen nae dattet ut sel scinen te wesen. Item waer dat yemant enighe broeder of suster van onser oerde of int ghemeen van der oerden enighe sonde valschelic opleide daer

53 vo. hi of si nae utwisinghe onser statuten die kerker mede rerdient hadde of alsulke sonden enighen waerliken personen, of die onder die obedienten onser oerden niet en stonden te kennen gave, daer der oerden of den persoen enighe scande of scade of quaem, dese soud men in die kerker setten ende daer niet atghelaten worden dan bi den capittel. Mer waer dien sonde heimelic of soud men daer een heimelic ondersoec of doen, ende setten haer penitenci naedat die tijt ende persoen eysschet.

Van den verlopen susteren $X X V I I J$ (capittel).

Is dat enighe suster wechloopt uter oerden mitter daet is si verbanct; welke sentenci wi nu gheren mit desen teghenwoerdighen statuten van welken ban si niet absolveert en mach worden dan van den visitierres of van den ousten prior. Wort yement begrepen in sijn wechlope ende teghen haren danc weder ghebrocht, die sel die correccie liden die voer gheseit is 
van dien die niet ghecorrigiert en willen wesen. Mer waert dat yemant die wechgelopen is willens weder quame ende begheerde ontfermherticheit, die en sel men gheensins weder ontfanghen in den convent, ist dat ment proeflic mach vermoeden dat si ghevallen sie in die sonde des vleischs, ten waer dattie vaders van onse capittel of die ouste prior als hem die sake claerlic ghetoent wort somtijts anders goetdochte. Ende wanneer men se ontfanghen sel, so sel si, al bloot ghemaket totten gordel toe, komen in den capittel ende nederlegghende bidden venia en sel alle die correctio liden, dairof ghesproken is ran swaerre. scult of ran den val des vleyschs of van tesamen spanninc, nochtans sel si van den penitencien die daer gheset syn meer of min langher of corter ontfanghen, nadat die voergaende ghebreken eysschen ende nae die teikenen der naevolghender penitencie. Hier eyndet die statuten. 